Published in "Ageing Research Reviews doi: 10.1016/j.arr.2013.03.004, 2013" which should be cited to refer to this work.

\title{
Notch signaling in the brain: In good and bad times
}

\author{
Lavinia Alberi $^{a, *}$, Sarah Hoey ${ }^{b}$, Emanuele Brai $^{a}$, Alessandra Scotti ${ }^{a, c}$, Swananda Marathe ${ }^{a}$ \\ a Unit of Anatomy, Department of Medicine, University of Fribourg, Switzerland \\ ${ }^{\mathrm{b}}$ Division of Psychiatry Research and Psychogeriatric Medicine, University of Zurich, Switzerland \\ c Institute of Anatomy, University of Bern, Switzerland
}

\begin{abstract}
Notch signaling is an evolutionarily conserved pathway, which is fundamental for neuronal development and specification. In the last decade, increasing evidence has pointed out an important role of this pathway beyond embryonic development, indicating that Notch also displays a critical function in the mature brain of vertebrates and invertebrates. This pathway appears to be involved in neural progenitor regulation, neuronal connectivity, synaptic plasticity and learning/memory. In addition, Notch appears to be aberrantly regulated in neurodegenerative diseases, including Alzheimer's disease and ischemic injury. The molecular mechanisms by which Notch displays these functions in the mature brain are not fully understood, but are currently the subject of intense research. In this review, we will discuss old and novel Notch targets and molecular mediators that contribute to Notch function in the mature brain and will summarize recent findings that explore the two facets of Notch signaling in brain physiology and pathology.
\end{abstract}




\section{Introduction}

In the name of nature's conservationist character, the mature brain employs an array of developmental pathways to regulate higher cognitive functions (Herz and Chen, 2006; Meffert and Baltimore, 2005; Speese and Budnik, 2007). Notch signaling is one of the best examples. This pathway is expressed throughout the lifespan of an animal from development (de la Pompa et al., 1997) to adulthood (Berezovska et al., 1998), and crosstalks with other signaling cascades in a context dependent manner.

Based on its temporally ubiquitous function, alteration to this cascade result from growth arrest (Swiatek et al., 1994) to brain diseases such as cerebral autosomal dominant arteriopathy with subcortical infarcts and leukoencephalopathy (CADASIL) (Arboleda-Velasquez et al., 2011), Alzheimer's disease (AD) (Berezovska et al., 1998; Steiner et al., 1999), Down syndrome (Fischer et al., 2005), stroke (Arumugam et al., 2006) and brain tumors (Dang et al., 2006; Pierfelice et al., 2011). The fact that Notch has such pleiotropic effects in the brain and other organs has posed a critical question in unraveling its role in the different cell types. Studies taking advantage of cre/loxP mouse genetics have been able to overcome the developmental requirement of Notch in embryonic growth and focus on the specific role of Notch in the mature brain and in a time-dependent manner (Table 1 ). In addition, Notch reporter mouse lines have provided spatial and temporal resolution of Notch signaling in the embryonic and mature brain, overcoming the paucity of good antibodies for Notch targets (Table 1). Taken together, mouse genetics tools have greatly improved our knowledge on the role of this signaling pathway in the postnatal brain. Following these strong advancements, remarkable work is ongoing to untangle the complexity of the Notch cascade in the mature brain. For a long time, it was thought that Notch activity in neurons was restricted to its transcriptional potential (Costa et al., 2003; Sestan et al., 1999). However, there are now numerous reports indicating that Notch crosstalks with other conserved pathways to complement its array of functions both in physiological (Alberi et al., 2011; Giniger, 1998; Hashimoto-Torii et al., 2008; Lugert et al.,
2010; Wang et al., 2004) and pathological conditions (Arumugam et al., 2006, 2011; Leal et al., 2012; Yang et al., 2004) (Fig. 1).

This review aims to summarize the most recent studies that have revealed some of the molecular mechanisms underlying Notch signaling in the mature mammalian brain. We will try to explain some of the unsolved mechanisms by looking into other biological settings, such as cancer and Drosophila biology, to find inspiration and support for future investigations.

Advances in understanding this cascade are highly relevant, not only for basic science, but offers a concrete potential for developing therapeutic strategies to counteract alterations in Notch signaling.

\section{The Notch pathway: an overview}

\subsection{The Notch pathway and its hallmarks}

The Notch pathway is highly conserved in metazoans (Gazave et al., 2009). It occurs early on in development, when cell-tocell contact determines morphogenesis (Artavanis-Tsakonas et al., 1999). Notch receptors are membrane-tethered proteins with characteristic epidermal growth factor (EGF)-like repeats on the extracellular portion (Rebay et al., 1991) and an intracellular transcriptional active site (Fortini and Artavanis-Tsakonas, 1994; Schroeter et al., 1998). In mammals, native Notch is cleaved at the endoplasmic reticulum (ER) by furin (S1 cleavage) that splits the extracellular and transmembrane portion into a mature receptor dimer held by a calcium $\left(\mathrm{Ca}^{2+}\right)$ bond. In vertebrates, there are four Notch receptor paralogues: Notch1, 2, 3 and 4. The receptors are activated by specific ligands of the Jagged and Delta serrate member families, which are expressed on the membrane of adjacent cells and contain a DSL (Delta-serrate-lag-2) motif, essential for binding to Notch (Lindsell et al., 1996; Nye and Kopan, 1995). When the juxtaposed ligand binds to Notch, dimerization of the receptor occurs (Mumm et al., 2000). The extracellular portion is endocytosed with the ligand in the adjacent signaling cell and the membrane bound portion of the receptor undergoes sequential processing (Parks et al., 2000) (Fig. 2). The second cleavage (S2)

Table 1

\begin{tabular}{|c|c|c|}
\hline Mouse model & Phenotype & Paper \\
\hline \multicolumn{3}{|l|}{ Notch1 LOF models } \\
\hline Notch1+/- & Learning and memory deficit & Costa et al. (2003) \\
\hline Notch1as & Synaptic plasticity deficit & Wang et al. (2004) \\
\hline$R B P J K+/-$ & Learning and memory deficit & Costa et al. (2003) \\
\hline Notch1f/f x T29-1CamK::cre & Synaptic plasticity and learning deficit & Alberi et al. (2011) \\
\hline RBPJKf/f $\times$ TgCamK::cre & Odor discrimination deficit (only females) & Sato et al. (2012) \\
\hline Notch1 f/f x CamKII::cre (CaMcre) & No phenotype detected & Zheng et al. (2012) \\
\hline Notch2 f/f x CamKII::cre (CaMcre) & No phenotype detected & Zheng et al. (2012) \\
\hline$R B P J K f / f \times$ Nes::cre $E R^{T 2}$ & Neurogenesis defect in SVZ & Basak et al. (2012); Imayoshi et al. (2010) \\
\hline$R B P J K f / f \times$ GLAST::cre $E R^{T 2}$ & Neurogenesis defect in SGZ & Lugert et al. (2010) \\
\hline Notch1f/f $\times$ Nes::cre $E R^{T 2}$ & Depletion of active NSC in SVZ & Lugert et al. (2012) \\
\hline \multicolumn{3}{|l|}{ Notch1 GOF models } \\
\hline Thy:: LSLNICD x G35-3::cre & Synaptic and visual plasticity deficit & Dahlhaus et al. (2008) \\
\hline \multicolumn{3}{|l|}{ Notch reporter mice } \\
\hline RBPJKRE::EGFP & Notch/RBPJK signaling reporter & Mizutani et al. (2007) \\
\hline RBPJKRE::nLacZ & Notch/RBPJK signaling reporter & Souilhol et al. (2006) \\
\hline pHes1:;dEGFP pHes5::dEGFP & Notch/RBPJK signaling reporters & Ohtsuka et al. (2006) \\
\hline Hes5:: EGFP & Notch/RBPJK signaling reporter & Basak and Taylor (2007) \\
\hline NIP-cre & Notch proteolysis reporter & Vooijs et al. (2007) \\
\hline Hes5-nlsLacZ & Notch/RBPJK signaling reporter & Imayoshi et al. (2010) \\
\hline Hes $1:: E m G F P S A T$ & Notch/RBPJK signaling reporter & Fre et al. (2011) \\
\hline Notch-GAL4VP16 & Notch activation dosage reporter & Smith et al. (2012) \\
\hline
\end{tabular}

Abbreviations: LOF, loss of function; GOF, gain of function; fl, flox allele; cre, cre recombinase; CamKII, calcium calmodulin kinase II; $E R^{T 2}$, estrogen receptor tamoxifen inducible 2; Nes, Nestin; GLAST, glutamate aspartate transporter; Thy, neuron specific promoter; LSL, Lox-Stop-Lox; EGFP, enhanced green fluorescent protein; dEGFP, destabilized enhanced green fluorescent protein; NIP, Notch intramembrane proteolysis; LacZ, $\beta$-galactosidase; EmGFP, emerald green fluorescent protein; GAL4, galactosidase activator protein; VP16, herpes simplex virus (HSV)-encoded transcriptional activator. 


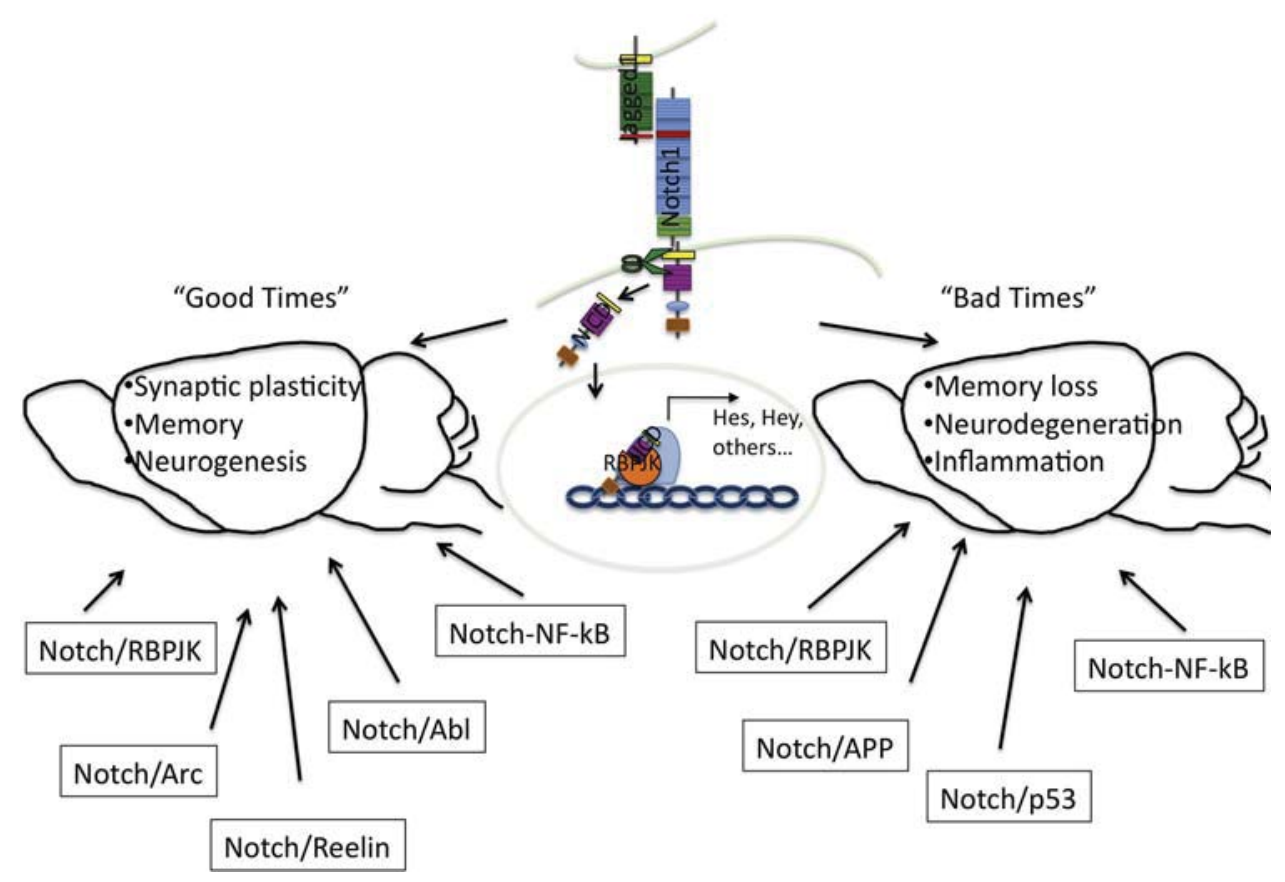

Fig. 1. Brain function and dysfunction through Notch signaling. Simplistic representation of the Notch/RBPJK signaling cascade, which is involved (arrows) in physiological brain functions ("good times") or pathological conditions ("bad times") in the mature brain. A sketch of a mouse brain is represented. Box indicating Notch crosstalks, which are involved in the two scenarios.

is then operated by disintegrin and metalloproteinases (ADAM17 and ADAM-10), while the transmembrane domain is available for $\gamma$-secretase processing. Presenilins (PS1 and PS2) of the $\gamma$ secretase complex generate the Notch intracellular domain (NICD) (S3-cleavage) (Mumm et al., 2000), and a transmembrane petide (Nß) (S4 cleavage) (Okochi et al., 2002) (Fig. 2).

In the canonical signaling, once NICD is generated, it is translocated to the nucleus through the binding of importins- $\alpha$ to its nuclear localization sequence (NLS) domain (Huenniger et al., 2010). Nuclear NICD associates with the transcriptional repressor RBPJK (recombination signal binding protein for immunoglobulin kappa J, also called CBF1, suppressor of hairless, lag-1), the co-activator protein MAML-1 (mastermind-like-1), and p300/CBP (CREB-binding protein), which possess histone acetyltransferase (HAT) activity and allows dissociation of the repressor complex formed by Skip (Ski-interacting protein), SMRT (nuclear receptor corepressor 2) and histone deacetylase (HDAC). This displacement converts RBPJK from a repressor to an activator (Kopan and Ilagan, 2009) (Fig. 2). The Notch-RBPJK complex initiate transcription of target genes, Hes (Hairy and Enhancer of Split in flies), Herp (Hesrelated proteins) (Iso et al., 2003), Sox2 (Ehm et al., 2010) and Pax6 (Kumar and Moses, 2001), that are involved in cell proliferation and stem cell maintenance. Notch/RBPJK signaling also controls expression of cell cycle regulators such as cyclinD1 (Ronchini and Capobianco, 2001) and cell growth factors as c-Myc (Palomero et al., 2007). In addition, a recent genome-wide analysis of NICD/RBPJK targets has identified, in embryonic forebrain progenitors, signaling components of the Wnt, Shh, Hippo and ionotropic glutamate receptor pathways as direct canonical targets (Li et al., 2012). Using high throughput technologies, this study has indicated, for the first time, a wide array of genes that are under Notch regulation. It is expected that Notch/RBPJK signaling, in development as well as in mature neurons, regulates many of these genes.

On the other hand, it appears that Notch also displays nontranscriptional activity that is essential for the crosstalk with other signaling components, including Rho-GTPase (Giniger, 1998), which mediates morphogenesis in differentiating neurons.
In the following sections we will discuss critical mechanisms that regulate Notch expression, transcriptional and non-transcriptional activity.

\subsection{The Notch receptors in the mature brain}

Notch1 is expressed in pyramidal neurons of the cortex (Redmond et al., 2000; Sestan et al., 1999; Stump et al., 2002) and hippocampus (Stump et al., 2002). Specifically in the hippocampus, Notch expression is induced by sensory experience and can behave as a novel "plasticity molecule": it is expressed postsynaptically and regulates spine morphology, synaptic plasticity and memory processing (Alberi et al., 2011; Costa et al., 2003; Wang et al., 2004). On the other hand, Notch1 is strongly induced following brain injury (Alberi et al., 2010; Arumugam et al., 2006) and may contribute to cell death. Notch2 expression pattern is similar to Notch1, however, it is expressed at lower levels in cortical and hippocampal neurons as compared to Notch1 (Stump et al., 2002). Notch2 is also critically upregulated upon injury and appears to contribute to brain damage (Alberi et al., 2010; Ferrari Toninelli et al., 2003). Notch3 is mostly expressed in astroglial progenitors (Tanigaki et al., 2001), choroid plexus (Dang et al., 2006) and vasculature (Joutel et al., 2000), whereas Notch4 has, so far, not been detected. On the whole, it appears that Notch expression is dynamically regulated and that alterations in pathway activity can interfere with physiological functions and affect cellular homeostasis.

\subsection{The Delta-serrate-lag-2 ligands and others}

The Notch ligands of the Jagged and Delta serrate member families are expressed on the membrane of adjacent signaling cells and contain a DSL-motif that is essential for binding to Notch (Lindsell et al., 1996; Nye and Kopan, 1995). In the mature brain, the ligands Jagged1 and Jagged2 are prevalent in the forebrain, whereas Delta-like1 and Delta-like3 are expressed at low levels in the cortex and the cerebellum, respectively (Stump et al., 2002). Our previous study confirmed that, in mature hippocampal 


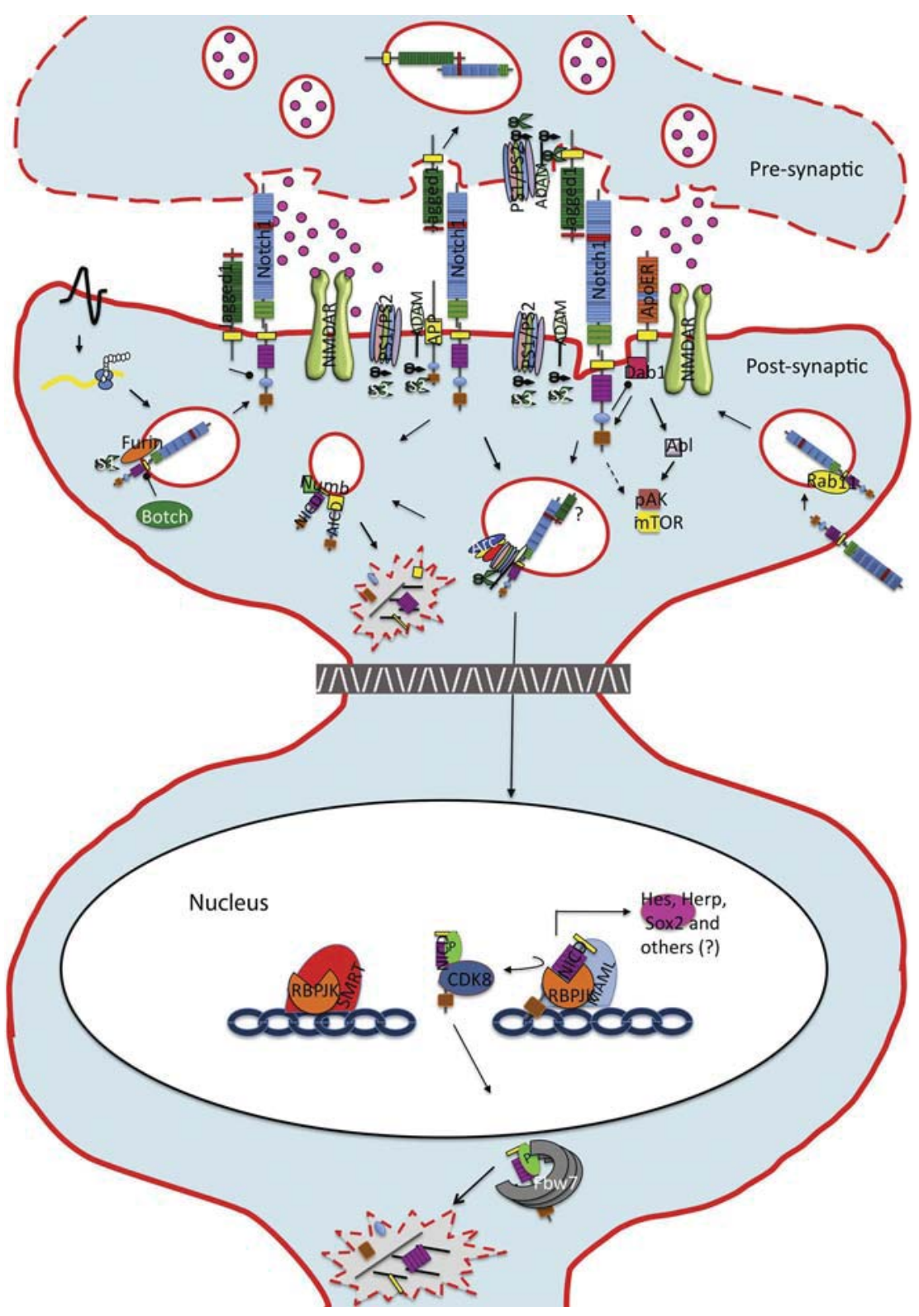

Fig. 2. Working model for Notch1 signaling in physiological conditions. Notch1 is expressed postsynaptically in the receiving cell whereas the ligand is expressed presynaptically in the signaling cell. Contact of Notch1 and Jagged1 ectodomains leads to dissociation of the extracellular portion of Notch and internalization in the signaling cell. Notch1 and Jag1 may be found at the same membrane side, in "cis" configuration, in which Notch activation is inhibited. In addition, the ligand may get processed/shedded at the presynaptic site and internalized with Notch in the receiving cell. Notch1 expression is regulated by furin cleavage (S1). Furin activity is under negative regulation of a novel protein "Botch" Notch1. Expression of Notch from pre-existing mRNA is activity dependent. Following activity Notch is rapidly recycled (Rab11) possibly from extrasynaptic to synaptic sites. Notch and APP are both expressed postsynaptically and following synaptic stimulation through NMDA receptors are cleaved at the membrane by proteases, ADAM (S2), Presenilin1 and 2 (PS1/2) (S3) are represented. NICD and AICD physically interact and reciprocally inhibit each other through Numb, which sends them to degradation. Notch interacts also with Reelin receptors (ApoER2 is represented) and they crosstalk through Dab/Abl signaling cascade. The trafficking of Arc/Arg3.1 facilitates NICD generation, through S3 cleavage, probably at the level of the endosome. NICD is internalized in the nucleus, displaces SMRT and binds to RBPJK and MAML to form a transcriptional complex that induces expression of specific target genes of the Hes and Herp gene family, Sox 2 and other known and yet unknown genes. NICD activity is negatively regulated by CDK8, which phosphorylates NICD and sends to degradation through Fbw7. The gray separation indicates the long-range distance between a dendritic synapse and the cell soma/nucleus.

neurons, Jagged 1 is prevalent and is expressed at presynaptic sites, whereas levels of Delta-like1 are negligible (Alberi et al., 2011). This also appears to be the case in the postnatal subventricular zone where Jagged 1 regulates proliferation of Notch-expressing neural stem cells (NSC) (Nyfeler et al., 2005). Interestingly, we have observed that, in mature neurons, the expression of Jagged1 increases in response to synaptic stimulation whereas Delta-like1 remains unchanged (Alberi et al., 2011). On the other hand, in Drosophila, Delta1 seems to be the relevant Notch ligand from development to the mature brain (Lieber et al., 2011; Muskavitch,
1994). It is not clear why ligand functions and topology are not conserved, but the separation of Delta and Jagged expression in different metazoan species has recently been reported (Gazave et al., 2009).

Additionally, Notch is induced by atypical ligands, that lack the DSL domain, such as Delta/Notch-like EGF related receptor (DNER) (Eiraku et al., 2002) and F3/contactin family members: MB3 and Contactin1 (D‘Souza et al., 2008). Interestingly, these ligands are expressed in dendrites, and axons (Kurisu et al., 2010; Pierre et al., 2001). 
On the whole, the presence of specific ligands on neuronal processes suggests that Notch signaling is required at distal synapses.

\section{Regulation of Notch availability}

Numerous reports have indicated critical checkpoints for Notch expression and signaling. In this section we will discuss some of the most recent findings in Notch expression and processing regulation.

\subsection{Translational and post-translational regulation}

It has recently been shown that in Drosophila embryogenesis, Notch signaling can be regulated at the level of ligand and receptor translation (Shepherd et al., 2009, 2010). The differential mRNA processing ensures the spatio-temporal dosage of the receptor and ligand, which is necessary for proper development. At present, we do not know whether RNA processing is differentially regulated in mammals. Nevertheless, we have shown that Notch is rapidly translated from pre-existing mRNA upon synaptic stimulation (Alberi et al., 2011) (Fig. 2). Interestingly, unpublished evidence from our group has indicated that Notch mRNA is localized at dendritic synapses, suggesting a requirement for readily available Notch transcripts at plasticity sites.

Moreover, it has recently been reported that a trans-Golgi protein, Botch, regulates S1 cleavage of Notch, which is critical for maturation of the Notch1 receptor (Chi et al., 2012). During neuronal development, Botch promotes neurogenesis by negatively regulating Notch expression. It remains to be understood how Botch function is regulated and whether Botch activity can influence Notch expression in neurons (Fig. 2).

Furthermore, glycosylation of the Notch receptor, by Ofucosylation and O-glycosylation of the EGF repeats, has been shown to be essential for proper signaling in Drosophila and mammals (Stanley, 2007). The O-fucosyltransferase, Pofut, mutant mice are viable but display $\mathrm{T}$ cell deficiency as a result of reduced Notchligand interaction and signaling (Ge and Stanley, 2008; Zhou et al., 2008). Two other reports using a zebrafish and a fucosylation loss of function mouse model, show that neuronal development and neuronal plasticity are affected, likely through impairment in Notch signaling (Song et al., 2010; Yagi et al., 2012).

Taken together, several mechanisms regulate Notch protein maturation thus granting proper signaling. It will be of interest to determine whether any of these mechanisms are affected during aging or following injury.

\subsection{Ligand mediated regulation}

There have been extensive investigations demonstrating the requirement for a membrane-tethered ligand to induce Notch activation in the signaling cell (Hicks et al., 2002; Lindsell et al., 1995; Nichols et al., 2007). It has been demonstrated that the E3 ubiquitin ligases, neuralized and mindbomb, promote Notch signaling by favoring the internalization of the ligand with the Notch ectodomain in the ligand-presenting cell (Le Borgne et al., 2005). Specifically, loss of Mindbomb-1 impairs Notch signaling and affects neuronal development and radial glia formation (Koo et al., 2007; Yoon et al., 2008). Thus, transactivation of the Notch receptor by the ligand, restricts the polarity of the Notch signal (del Alamo and Schweisguth, 2009).

Several reports using Drosophila have shown that when the ligands, Delta or Serrate, and the Notch receptor are proximal at the membrane of the same cell, in "cis" configuration, they exert a ligand-mediated blockade on Notch activation through their intracellular domain (de Celis and Bray, 1997; Glittenberg et al., 2006; Miller et al., 2009) (Fig. 2). More recently it has been shown that also Notch, through its extracellular portion, can exert a block on Serrate mediate Notch activation (Becam et al., 2010). These findings indicate a mutual inhibitory interaction between ligand and receptor when present at the membrane of the signaling cell. The "cis" inhibition of ligand and receptor, in mammalian cells, has been confirmed using a neuroblastoma cell line by overexpressing Delta, which leads to neurite extension. Conversely, when Delta is expressed on fibroblasts, it induces neurites shortening by transactivating Notch (Franklin et al., 1999). In mammalian neurons, the ligand Jagged 1 is expressed in presynaptic terminals juxtaposed to Notch, which is mainly expressed and induced postsynaptically (Alberi et al., 2011). Interestingly, it appears that, in Drosophila sensory neurons, this configuration is inverted: the Delta ligand is expressed postsynaptically, whereas Notch is present presynaptically (Lieber et al., 2011). Therefore, also in the mature brain, spatial separation of the ligand and receptor appears to grant signaling directionality.

Furthermore, it has been shown that soluble ligands can compete with the membrane-bound counterparts and repress signaling (Hicks et al., 2002; Varnum-Finney et al., 2000). There are, however, several reports showing that bath application of soluble ligands, containing the DSL binding site for Notch, can lead to Notch activation in neurons, neuronal stem cells and other mammalian cell lines (Androutsellis-Theotokis et al., 2006; Kyriazis et al., 2010; Wang et al., 2004). The presence of a soluble ligand has been confirmed in a recent paper indicating constitutive ligand shedding by ADAM-17 (Parr-Sturgess et al., 2010).

On one side, it appears that a membrane anchored receptor-ligand interaction is essential for signaling, while, on the other hand, experimental evidence suggests the presence of a functionally active soluble ligand. This apparent discrepancy will need to be further investigated. Nevertheless, it raises the possibility that internalization of the Notch ectodomain with the ligand in the signaling cell might not be an absolute requirement for Notch activation, and that alternative mechanism of Notch activation may take place. In the next chapter, we will discuss some of these putative mechanisms.

\subsection{Endocytic internalization of Notch}

It remains a topic of debate as to whether Notch processing occurs at the membrane or in the endosomal compartment. A recent study suggests that $\gamma$-secretase cleavage at the plasma membrane generates a more efficient form of NICD (NICD-V), whereas S3-cleavage in the endosome produces two short-lived NICD forms: NICD-L and NICD-S (Tagami et al., 2008). This work also showed that some FAD mutations of Presenilin 1 affect the precision of S3-cleavage, which may contribute to diminished Notch signaling (Tagami et al., 2008). It would be of interest to know if, in neurons, these labile forms are generated when NICD signal is not required. Interestingly, most of the NICD we observe in long-term neuronal culture and cortical neurons, is localized in the cytoplasm, and very little is present in the nucleus in contrast to maturing (Redmond et al., 2000) or injured neurons (Arumugam et al., 2011).

It has previously been reported that endocytic processing of Notch is associated with weaker signaling, due to ubiquitination and degradation via Numb, which is a conserved intracellular modulator of Notch (Jafar-Nejad et al., 2002) (Fig. 2). Interestingly, Numb associates with Cdc24, EphB2, NMDAR (Nmethyl-D-aspartate receptor) postsynaptically and contributes to spine development (Nishimura et al., 2006). It would be interesting to know whether Numb regulates the levels of Notch at the synapse (Fig. 2).

Endosomal trafficking, however, appears instrumental for Notch activation since systematic deletion of endocytic components, in Drosophila, leads to accumulation and overactivation of Notch 
(Vaccari and Bilder, 2005; Vaccari et al., 2008). This study reveals that endosomal trafficking exerts a necessary dampening effect on Notch signaling. In addition, recent work has indicated that Notch activation at the endosome, occurs independently of the ligand (Childress et al., 2006; Hori et al., 2011). This might explain why, in neurons, Notch processing is positively regulated by the endosomal trafficking molecule, Arc, regardless of ligand availability (Alberi et al., 2011) (Fig. 2). Additionally, we have preliminary evidence indicating that, upon synaptic stimulation, Notch is rapidly internalized into early endosomes and recycled to the surface (Fig. 2). We are currently investigating whether the recycling of Notch is directed from extrasynaptic to synaptic sites upon physiological stimulation (Fig. 2).

Based on the evidence that Notch is present at distal postsynaptic sites and Presenilins activity is maximal at the endosome ( $\mathrm{Wu}$ et al., 2011), we argue that under physiological conditions, endocytic trafficking and processing might be prevalent.

\section{Notch signaling regulation}

\subsection{Extrinsic modulatory influences on Notch signaling}

There is growing evidence suggesting that Notch signaling is susceptible to extrinsic factors. It has recently been reported that ADAM activity can be induced by synaptic stimulation (Hoey et al., 2009) and PKC activation (Cisse et al., 2011). Synaptic stimulation can also induce $\gamma$-secretase activity at the endosome through the clustering of the complex Arc/Presenilin1 to its substrates (Wu et al., 2011). Interestingly, Notch activation, in response to increased activity, occurs in mature neurons (Alberi et al., 2011; Lieber et al., 2011) and in neural stem cells of the mature brain (Lugert et al., 2010). This suggests that activity dependent Notch signaling may be a signature of mature Notch function.

Notch and the amyloid precursor protein (APP) share common processing mechanisms through ADAM and $\gamma$-secretase, and both substrates are processed in an activity dependent manner (Alberi et al., 2011; Hoey et al., 2009). Early reports suggest that Notch 1 and APP coprecipitate in brain lysates and that they interact through their transmembrane domain (Fassa et al., 2005; Kim et al., 2007). It was also shown that the APP intracellular domain (AICD), through interaction with Numb, can down-regulate Notch signaling (Roncarati et al., 2002) (Fig. 2). It appears, therefore, that APP and Notch have complementary functions. Nevertheless, it has been recently proposed that the interaction between Numb and Notch can be reverted upon stress conditions. This study showed that trophic factor withdrawal induces a switch in Numb isoform to a shorter phosphotyrosine-binding domain (Numb-SPTB) that favors endocytic sorting/processing of Notch (Kyriazis et al., 2010) (Fig. 3). Therefore, in light of this study, we may hypothesize that APP and Notch interaction through Numb is either negative or positive depending on the cellular homeostasis. It will be interesting to know whether aberrant synaptic activity as in AD and epilepsy (Palop and Mucke, 2009) can facilitate Notch signaling through APP-Numb-SPTB induction.

One other study showed that, in Drosophila blood cells, Sima, the protein orthologous to the mammalian hypoxia-inducible factoralpha (Hif- $1 \alpha$ ), is a strong activator of Notch independently of the ligand (Mukherjee et al., 2011) (Fig. 3). It is currently unknown whether high levels of Hif- $1 \alpha$ can activate Notch, in the mammalian brain, following cerebral ischemia (Chavez and LaManna, 2002).

Additional studies might help understand the underlying mechanism of Notch responses to homeostatic changes.

\subsection{Regulation within the nucleus}

Notch transcriptional activity is tightly regulated also at the level of nucleus. The half-life of the transcriptionally active NICD-RBJK complex is determined by MAML- 1 . MAML- 1 recruits cyclin dependent kinase-8 (CDK8) to nuclear foci and allows phosphorylation of NICD (NICD-P) and targeting of NICD-P for proteosomal degradation by E3 ubiquitin ligase Fbw7 (Fryer et al., 2004) (Figs. 2 and 3). Recent work indicates that degradation of NICD by Fbw7 is essential for neural stem renewal and differentiation: genetic deletion of Fbw7 leads to NICD accumulation, progenitors' apoptosis (Hoeck et al., 2010) and neuronal-glial fate commitment (Matsumoto et al., 2011). However, in these studies it was not shown whether accumulation of NICD affects expression of Notch1 protein levels as part of a positive feedback loop. Notch1 self-regulation has been reported in Drosophila (Del Monte et al., 2007) and murine embryonic neural stem cells (Li et al., 2012).

RBPJK forms a constitutive repressor complex when associated to Skip/SMRT/HDAC. A recent report using mammalian cell lines has indicated that Wnt5a, through CamKII, can facilitate the export of SMRT, enabling the interaction of Notch to the RBPJK transcriptional complex (Ann et al., 2012). Interestingly, Wnt5a regulates spine morphogenesis and synaptic plasticity (Varela-Nallar et al., 2010). It is intriguing to hypothesize that this effect is achieved through Notch function.

In addition, the Drosophila ortholog of Hif- $1 \alpha$, has a stabilizing effect on the Notch-RBPJK transcriptional complex (Gustafsson et al., 2005) (Fig. 3). It is possible that Hif- $1 \alpha$, which is strongly induced by ischemia (Chavez and LaManna, 2002), can potentiate Notch signaling in injury.

These and other yet undiscovered mechanisms might explain the signaling power of Notch in physiological and pathological conditions.

\section{Notch crosstalking to other signaling pathways}

Several studies have shown that the membrane-tethered form of the Notch receptor and the activated NICD display signaling capacity through the interaction with other signaling pathways (Andersen et al., 2012; Le Gall et al., 2008; Sanalkumar et al., 2010). In the next sections we will highlight significant crosstalks with putative neuronal function. We believe that studies in this field are the foundation to understand the pleiotropic role of Notch in the mammalian brain.

\subsection{Cytoplasmic crosstalk}

The work of Giniger on Notch/Abl (Abelson tyrosine-protein kinase) signaling in axon patterning, in Drosophila, has pioneered this research avenue. In various papers, the work from this group has demonstrated that cytoplasmic Notch, lacking the transcriptional active site, can effectively repress Abl signaling, by binding to Disabled and Trio, thereby controlling axonal growth/guidance (Crowner et al., 2003; Giniger, 1998) (Fig. 2). This suggests that at distal sites from the nucleus Notch cooperates with local signaling mechanism to display morphogenic functions.

Interestingly in mammals, Disabled is found downstream of Reelin receptors and it is instrumental for Reelin signaling (Herz and Chen, 2006). It has, also, been shown that Reelin stabilizes Notch signaling through the interaction with Disabled1 in developing neurons (Hashimoto-Torii et al., 2008) (Fig. 2). In addition, dendritic maturation in Reeler (Reelin deficient) mice can be rescued by NICD expression (Hashimoto-Torii et al., 2008). Another study revealed that Reelin deficiency leads to a strong reduction in Notch activation and canonical signaling in the developing 

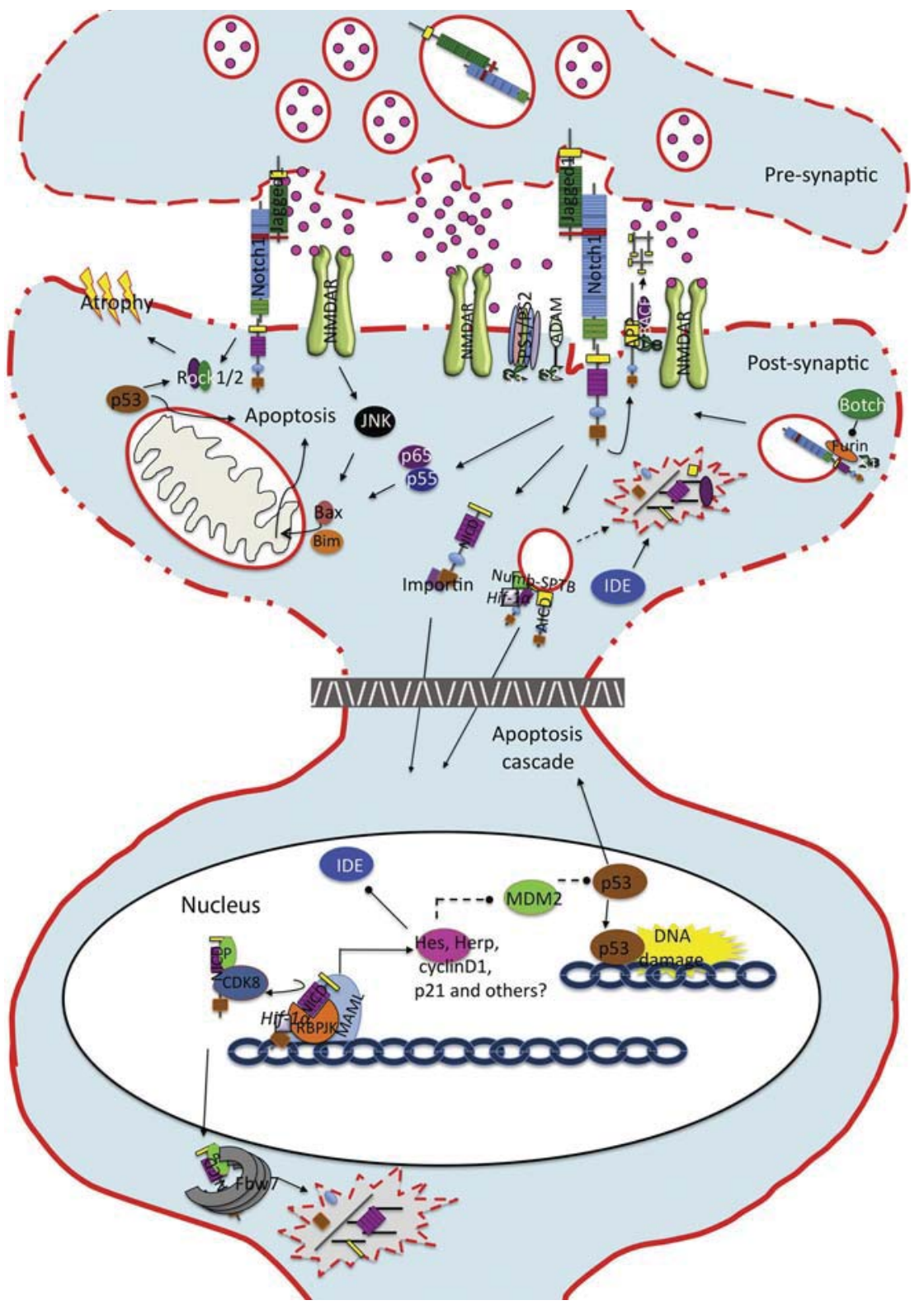

Fig. 3. Working model of Notch1 signaling in pathological conditions. Following injury, as in hypoxia-ischemia, Notch1 is rapidly processed through S2 and S3 clevage and induces pathway activation. Notch1 levels are also increased probably in response to a positive Notch-CSL feedback. It is possible that Botch, which blocks S1 cleavage influencing Notch1 expression, is directly involved in this process. NICD is stabilized by the interaction with Hif- $1 \alpha$. A stress-dependent Numb isoform (Numb-SPTB) favors NICD-CSL activity. Notch1, through still unresolved mechanisms, positively interacts with NF-kappaB/JNK pathway to mediate mitochondrial translocation of cytosolic enzymes inducing apoptosis. NICD might be preferentially trafficked to the nuclei by importin $\alpha / \beta$, which are rapidly induced following injury. NICD, once in the nucleus, induces activation of downstream targets of the Hes, Herp gene families and other context dependent genes as cyclinD1 and p21. Hes1 may downregulate ubiquitin ligases MDM2 and IDE. Down-regulation of MDM2 stabilizes and thereby increases p53 levels which triggers the apoptotic cascade. p53, senses DNA damage, cooperates with Notch also in neurites retraction through Rho-GTPases (Rock1/2). Hes1 activation leads to down-regulation of IDE. This de-represses activation of BACE, through increase in AICD, and leads to transition from non-amylogenic to amylogenic $A \beta$ production. The gray separation indicates the long-range distance between a dendritic synapse and the cell soma/nucleus.

hippocampus (Sibbe et al., 2009). This raises the possibility that some of the traits observed in the various Reelin mutant mouse models, such as decreased synaptic plasticity and spatial learning (Beffert et al., 2005; Weeber et al., 2002) may underlie impaired Notch signaling.

Additional evidence that Notch might be instrumental in neuronal function through non-canonical neuronal modulator comes from the work indicating that Notch interacts with the mammalian target of rapamycin (mTOR)-Akt pathway. This pathway is essential in memory formation (Bekinschtein et al., 2007) and consolidation (Hoeffer et al., 2008). An interesting parallel between Notch and mTOR function can be found in the common LTD deficiency observed in hippocampal slices treated with PI3K-AktmTOR inhibitors (Hou and Klann, 2004) and the Notch1cKOs (Alberi et al., 2011). A mechanistic interaction has been shown in HeLa and embryonic stem cells. In the first study, trophic factors removal can induce Akt phosphorylation, through the interaction of NICD with mTOR and the independent companion of mTOR (Rictor), independently of Notch/RBPJK signaling (Perumalsamy et al., 2009) (Fig. 2). On the other hand, it has been reported that application of soluble Notch ligands can induce phosphorylation of Akt and mTOR in stem cells, which can be blocked by inhibiting Notch processing (Androutsellis-Theotokis et al., 2006). It is intriguing to hypothesize that such a positive interaction might take place also in neurons. 
At this point, it is mandatory to understand whether dysfunction in the mTOR-Akt pathway occurs in Notch1cKO neurons.

Other relevant work, that puts Notch in connection with another pathway involved in synaptic plasticity, indicates that Notch negatively regulates Wnt signaling by favoring degradation of $\beta$-catenin. This negative interaction seems to be facilitated by Numb (Kwon et al., 2011). Interestingly, both Notch and Wnt cascade components are expressed postsynaptically, are triggered by NMDA transmission and influence synaptic plasticity (Alberi et al., 2011; Ataman et al., 2008; Nishimura et al., 2006). A behavioral study has shown that during memory consolidation, levels of Notch were reduced, whereas $\beta$-catenin expression was increased (Conboy et al., 2007). It will be of interest to understand whether these components characterize specific memory traces.

Another remarkable interaction is the crosstalk between Notch and NF- $\kappa$ B signaling. NF- $\kappa$ B denotes a dimeric transcriptional complex composed by p55:p65. Interestingly, this dimer is found at synapses and can respond to increase in local $\mathrm{Ca}^{2+}$ transients (Meffert et al., 2003). It has been shown that these pathways have synergistic functions in physiological conditions and in brain injury. The Notch antisense mice (Notch1as), in which Notch is partially deleted (50-70\%) using an antisense interference strategy (Cheng et al., 2001), display specific synaptic plasticity defects coupled with reduction in NF- $\mathrm{B}$ binding activity (Wang et al., 2004), suggesting that Notch regulates NF- $\kappa$ B signaling. Interestingly, p65 mutant mice display defects in learning/memory processing (Meffert et al., 2003) similar to the Notch1+/- and Notch1cKO mice (Alberi et al., 2011; Costa et al., 2003). This positive interaction has been investigated more extensively in a hypoxia-ischemia injury paradigm. Arumugam and colleagues have shown that Notch activation in an ischemia-like injury model is coupled with activation of the NF- $\kappa B$ pathway and can be blocked by application of several $\gamma$-secretase inhibitors both in vitro and in vivo (Arumugam et al., 2006, 2011) (Fig. 3). The latest study from this group indicated that nuclear NICD is essential for NF- $\mathrm{B} / \mathrm{JNK}$ activity, although the molecular mechanism remains yet unraveled.

It appears, however, that NF- $\kappa \mathrm{B}$ activity can also regulate Notch signaling. Reports revealed that Jagged 1 is a direct target of NF$\kappa \mathrm{B}$ (Bash et al., 1999) and that NF-кB influences Notch signaling by favoring the translocation of the nuclear corepressor of RBPJK (Espinosa et al., 2002). Therefore Notch and NF-кB pathway appear to synergize in a positive feedforward and feedback mechanism. Nevertheless, a recent investigation from Bonini has challenged this hypothesis and has shown that, in hippocampal cultures from p50 mutant mice, Jagged1 is overexpressed and triggers increased Notch signaling. In addition, the authors claim that, as a result of Notch activation, less dendritic branching is observed (Bonini et al., 2011). This is somewhat surprising considering that Notch promotes dendritic branching (Breunig et al., 2007; Redmond et al., 2000). It remains possible that the effect of Notch on dendritic morphology is partially mediated by NF- $\mathrm{\kappa B}$ signaling. Another possibility is that overactivation of Notch results in neurites retraction and cell death. This latter point is of further interest because, if the authors did not observe any sign of cell death, it would emphasize that these pathways function together in mediating neuronal cell demise.

Studies looking at cytoplasmic interactions between Notch and other signaling components will advance our understanding of Notch signaling in the mature brain dramatically.

\subsection{Nuclear crosstalk}

We, and others, have observed that under physiological condition, Hes 1 and Hes5 expression (as readout of Notch-CSL signaling) appear unresponsive to changes in Notch activity (Alberi et al., 2011; Yu et al., 2001), whereas under ischemic condition there is a strong up-regulation of Notch/RBPJK targets (Alberi et al., 2010; Arumugam et al., 2006). We may speculate that, following injury, Notch undergoes rapid Importin-mediated trafficking and nuclear signaling is favored (Huenniger et al., 2010) (Fig. 3). After axonal injury, Importins- $\alpha / \beta$ are rapidly translated in situ and function as proteins' carrier from the periphery to the nucleus, mediating either pro survival or death signals (Hanz et al., 2003). This would be in line with another work indicating that another Notch target, cyclinD1, is induced following stroke (Timsit et al., 1999) (Fig. 3). Interestingly, cyclinD1 heterozygous mice display partial neuroprotection following kainic acid injury (Koeller et al., 2008), suggesting that Notch signaling might be instrumental in the life/death choice.

In addition, Notch and APP proteins are aberrantly regulated in Alzheimer's disease (Woo et al., 2009). Notch and APP appear to have a mutual positive feedback on downstream targets (Fischer et al., 2005). This would suggest that APP and Notch cooperate at the level of transcription. Indeed, it has been shown that AICD and NICD are found in nuclear factories in association with the effector protein Fe65 (Konietzko et al., 2010). Another more recent study indicates that Notch transcriptional activity, through Hes1, regulates APP metabolism leading to de-repression of BACE-1 and an increase in the production of $A \beta_{42}$ insoluble peptides that concentrates in amyloid plaques (Leal et al., 2012) (Fig. 3). This report is very intriguing and indicates for the first time a direct regulation of APP processing by Notch and a potential critical interaction in the pathobiology of Alzheimer's disease.

There is additional evidence emerging from work in neurodevelopment and differentiation that Notch cooperates with another cell death signal, Trp53 (p53). Mice conditionally expressing NICD under the Nestin promoter, displayed increased apoptosis of neuronal progenitors during development. Apoptosis was coupled with aberrant increase in p53 pathway activity and was rescued by genetic ablation of p53 (Yang et al., 2004). The positive feedback of Notch on p53 has also been observed in mouse fibroblasts. One study indicated that Notch activation, through Notch/RBPJK activity, de-represses p53 expression by inhibiting the ubiquitin ligase, MDM2, which degrades p53 (Huang et al., 2004) (Fig. 3). Another investigation using mouse fibroblasts, lacking the ubiquitin ligase Fbw7, showed that Notch activation is linked to p53 upregulation in mediating cell cycle arrest (Ishikawa et al., 2008). A mutual positive feedback of p53 on Notch activity has also been recently reported: p53, by sensing DNA damage, activates an apoptosis cascade in neuronal stem cells and contributes, together with Notch, to reducing neurites' length through the action of the small GTPase RhoA kinases, Rock1 and Rock2 (Ferron et al., 2009)(Fig. 3). Similar results have been obtained in keratinocytes (Lefort et al., 2007). From these studies it appears that p53 and Notch functions are closely correlated in life/death decision and neurites' morphogenesis.

On the whole, it appears that Notch signaling is intertwined with multiple conserved pathways also at the nuclear level. Future studies will help address how these different crosstalks are fine-tuned to mediate adaptive changes in neurons.

\section{Notch in good times}

\subsection{Notch in synaptic plasticity}

When looking at the temporal expression pattern of Notch in the cortex, it is interesting to observe that, around birth, Notch1 expression is attenuated as compared to development. However, after the first postnatal week, expression becomes more abundant (Tokunaga et al., 2004). This time coincides with the critical period when synaptic connections are being refined and spontaneous synchronized activity patterns synaptic connections (Garaschuk 
et al., 2000). We might therefore hypothesize that during postnatal development, Notch is induced and required for network maturation. Several papers have confirmed this hypothesis and have shown that Notch has a direct effect on dendritic patterning (Berezovska et al., 1999; Breunig et al., 2007; Redmond et al., 2000; Sestan et al., 1999) and axonal outgrowth (Crowner et al., 2003). We now know, from several studies, that reduction in Notch signaling affects sensory and memory processing across several species (Alberi et al., 2011; Chao et al., 2005; Costa et al., 2003; Ge et al., 2004; Wang et al., 2004). This effect does not appear to be the result of aberrant connectivity, but rather depends on changes in synaptic plasticity (Alberi et al., 2011). Interestingly, the plasticity deficit in the Notch1cKO does not completely phenocopy the loss of Presenilin1/2 (PS1/PS2; PsdcKO) (Saura et al., 2004). In the PsdcKO mice, the LTP deficit is accompanied by reduced presynaptic release, which can neither be observed in the Notch1cKOs nor in Notch1as mice. This suggests that Presenilin1/2 may also regulate essential functions of presynaptic substrates that influence neurotransmitter release. The postsynaptic function of Notch is also supported by the fact that bath application of Jagged 1 potentiates LTP (Wang et al., 2004).

Interestingly, a more recent report indicates that conditional deletion of Mindbomb-1, which is instrumental for ligand endocytosis and Notch signaling (Koo et al., 2005), leads to a synaptic plasticity and memory deficit (Yoon et al., 2012). This provides additional evidence that, in the mature brain, Jagged 1 might be instrumental for Notch-dependent plasticity. Interestingly, Alagille patients, carrying genetic mutation for Jagged1, besides the liver and heart pathology, also display signs of mental retardation (Alagille et al., 1975). It would be of interest to know whether this is the result of impaired connectivity or plasticity in the brain.

Canonical Notch signaling has been shown to be critical for spatial learning and memory, based on the evidence that RBPJK heterozygous mice display a similar deficit as the Notch heterozygous mice (Costa et al., 2003). Nevertheless, a recent paper has shown that postnatal deletion of RBPJK does not affect memory and learning (Sato et al., 2012). This study concludes that Notch/RBPJK signaling is dispensable for synaptic plasticity. In addition, NICD overexpression in pyramidal neurons of the visual cortex reduces spine density and represses long-term potentiation (Dahlhaus et al., 2008). This suggests that ectopic NICD interferes with physiological Notch functions and/or that non-transcriptional Notch activity is instrumental in neuronal physiology. In this direction, a study in Drosophila has indicated that the adhesion molecule, Klingon, is a direct non-canonical/non-transcriptional target of Notch in a memory paradigm, and that it is instrumental for long term memory formation (Matsuno et al., 2009). This study is very intriguing and suggests that non-canonical mediators of Notch may be involved in synaptic plasticity and memory processing.

On the whole, it appears that transient increase of Notch in response to activity is essential in synaptic plasticity modulation (Alberi et al., 2011; de Bivort et al., 2009; Lieber et al., 2011). Nevertheless it has been shown that Notch signaling is attenuated during the period of memory consolidation (Conboy et al., 2007). This raises the interesting possibility that Notch signaling is responsible for early rather than late molecular changes at the synapse following potentiation.

Ultimately, these studies highlight that Notch signaling is an essential requirement for neuronal function and memory formation.

\subsection{Notch in postnatal neurogenesis}

In the mature brain, Notch signaling is additionally implicated in adult neurogenesis of the subventricular zone (SVZ) (Basak et al., 2012; Imayoshi et al., 2010; Nyfeler et al., 2005) and subgranular zone of the hippocampus (SGZ) (Lugert et al., 2010). Neurogenesis, and integration of new born neurons is thought to contribute to olfaction (SVZ) (Sakamoto et al., 2011) and spatial memory (SGZ) (Kempermann and Gage, 2002).

Canonical Notch/RBPJK signaling is essential in maintaining a neurogenic pool in the mature brain (Basak et al., 2012; Imayoshi et al., 2010; Lugert et al., 2010). It has been shown that ablation of RBPJK in adult neural stem cells (NSCs) of the SVZ induces a transient increase in neurogenesis but leads in the long term to a permanent depletion of the progenitor pool (Imayoshi and Kageyama, 2011). Another recent study, using conditional deletion mouse models for Notch1 and RBPJK in adult NSC of the SVZ, has confirmed that loss of functional Notch signaling exhausts the progenitor pool (Basak et al., 2012). This same study indicates a functional separation between Notch1 and RBPJK function and indicates that Notch1 does not regulate the cell fate of quiescent NSCs, which, instead, appears to be under RBPJK regulation, probably through the other heterologous receptors, Notch2 and Notch3. The group of Taylor has also demonstrated, at least in two papers, that Notch1 is important in maintaining an actively proliferating NSCs pool, which selectively lost during aging (Basak et al., 2012; Lugert et al., 2010).

Work from the same group has indicated that, similar to the SVZ, ablation of RBPJK in NSCs of the postnatal DG leads to a strong depletion in progenitor cells (Lugert et al., 2010). Using a Notch reporter line, in which cells with ongoing Notch/RBPJK are GFP labeled (Hes5::GFP), the authors found that NSCs of SGZ with Notch/RBPJK signaling are the most multipotent of the total progenitors. In basal conditions these NSCs are, for the large part quiescent, but can rapidly switch into a neurogenic mode in response to maximal activity or exercise (Lugert et al., 2010, 2012). This important study indicates that the regenerative potential of neuronal progenitors is responsive to increased synchronized activity. As a matter of fact, neurogenesis in the SGZ can be induced by exercise (van Praag et al., 1999), environmental enrichment (Brown et al., 2003) and synaptic potentiation (Kameda et al., 2012). Other extrinsic sensory factors, as olfaction, can increase neurogenesis in the SVZ (Rochefort et al., 2002). We may hypothesize that this process is mediated by activity-dependent Notch activation, although other signaling pathways, such as PI3K/AKT (Bruel-Jungerman et al., 2009), BDNF/TrkB (Bergami et al., 2009) and Wnt signaling (Lie et al., 2005) have also been implicated in these processes.

Beside the role in neural stem maintenance, Notch also regulates integration of newborn neurons in the granule cell layer (Breunig et al., 2007). Various studies using animal models have shown that, during aging (Ben Abdallah et al., 2010; Lugert et al., 2010) and Alzheimer's disease, neurogenesis is considerably reduced (Jaskelioff et al., 2011; Rodriguez et al., 2008, 2009). In addition, several loss of function of Presenilins display reduced neurogenesis (Chen et al., 2008b; Chevallier et al., 2005; Faure et al., 2011). Despite the multiple targets of $\gamma$-secretase, we believe that, in light of the recent findings, perturbation in Notch may contribute to the deficit in neurogenesis observed in these studies.

Therefore Notch signaling appears instrumental for the regenerative capacity of the mature brain.

\section{Notch in bad times}

\subsection{Notch in Alzheimer's disease}

Notch signaling has often been implicated in AD, however, at present, the mechanisms involving Notch in progressive neurodegeneration remains elusive. Several familial AD (FAD) mutations of Presenilin1, leading to early onset dementia, are associated with diminished Notch activity (Chavez-Gutierrez et al., 2012; 
Moehlmann et al., 2002; Steiner et al., 2001). In addition, FAD mutations of presenilin produce longer and more lipophilic $N \beta$ peptides in analogy to the amylogenic $A \beta_{42}$ at the expense of the non-amylogenic $A \beta_{40}$ forms (Okochi et al., 2002). $A \beta_{42}$ are responsible for insoluble amyloid plaque formation. The efficiency of $\gamma$-secretase appears to be affected during aging. In fact, in the brains of aged mice, $\gamma$-secretase activity increased APP processing and $A \beta_{42}$ production, whereas Notch1 processing is reduced (Placanica et al., 2009).

In contrast to the previous reports indicating a reduction in Notch activity in AD, two other studies showed a significant increase in Notch expression/activity in sporadic Alzheimer's disease (Berezovska et al., 1998; Nagarsheth et al., 2006). In addition, other neurodegenerative diseases such as Down syndrome (Fischer et al., 2005), Pick's (Nagarsheth et al., 2006) and Prion's disease (Ishikura et al., 2005), are characterized by concomitant increases in Notch expression and amyloid plaques formation. It remains to be understood why progressive neurodegenerative diseases have different mechanisms in terms of Notch processing and signaling, and whether Notch effectively contributes to their pathobiology.

Beside the unresolved role of Notch in $\mathrm{AD}$, the common processing mechanism of Notch and APP has posed serious challenges in the development of drugs that can counteract the progression of AD: Pre-clinical trials using $\gamma$-secretase inhibitors have reduced amyloid plaques deposition but have often caused intestinal bleeding and immunosuppression due to the inhibition of Notch signaling (Wong et al., 2004). Therefore, in recent years, more compounds have been developed that target APP metabolism without affecting Notch signaling (Wolfe, 2012). These novel drugs might improve not only the peripheral actions of the compounds, but also spare Notch signaling in the brain.

Further studies aimed at unraveling the molecular mediators of Notch-dependent processes in progressive neurodegenerative disease will further contribute to the development of better preventive and therapeutic strategies to counteract imbalances in Notch signaling in aging and AD.

\subsection{Notch in ischemic injury}

Several studies have shown that, following ischemic injury, Notch signaling is aberrantly up-regulated (Alberi et al., 2010; Arumugam et al., 2006; Lou et al., 2012; Shimada et al., 2011). Notch induction following injury results in a plethora of effects and can contribute to damage as well as regeneration. In mature neurons, Notch1 (Arumugam et al., 2006) and Notch2 (Arumugam et al., 2011; Ferrari Toninelli et al., 2003) are both induced, suggesting a summation of downstream effects.

The involvement of Notch in ischemia-induced cell death has been further shown by the work of Arumugam et al. (2011), where Notch appears to interact with the NF- $\kappa B$ components p65, p50 and Bim in the apoptotic process in vitro and in vivo (Fig. 3). The only caveat of this latter study is the chemical in vivo loss of function model utilized ( $\gamma$-secretase inhibitors $[\gamma \mathrm{GSI}]$ ). These drugs inhibit the processing of several $\gamma$-secretase substrates at the same time (Selkoe and Wolfe, 2007) and it is therefore difficult to study specific implications of Notch signaling in any of these processes. Employing genetic loss of function along with GSI is strongly recommended to understand the clinical relevance of this pathway.

Another recent study, using both GSI and a Notch loss-offunction model, has shown that Notch signaling is crucial for inducing NF- $\mathrm{\kappa B}$ driven microglia responses, similar to what occurs in mature neurons (Wei et al., 2011). The microglial response upon injury is notorious for producing an immuno-inflammatory response that can worsen and amplify neuronal damage (Stoll et al., 1998). Similarly, another recent study indicates that Notch 1 is directly involved in reactive gliogenesis, contributing to the cell invasion in the peri-infarct area (Shimada et al., 2011).

Following cerebral ischemia, angiogenesis and vessel sprouting takes place. Notch1 is an important angiogenic factor both during development (Limbourg et al., 2005) and postnatally (Takeshita et al., 2007). It appears that, following cerebral ischemia, Notch plays an important role in reperfusion and the reorganization of the microcirculation (Lou et al., 2012). Besides Notch1, Notch3 plays a fundamental role in the vasculature, where it is specifically expressed in smooth muscle cells of the endothelium. Mutations in the Notch3 genes induce CADASIL, which is characterized by progressive brain ischemia and vascular dementia (Dichgans, 2007). Notch3 mutant mice have confirmed the fundamental requirement of Noch3 in vasculature reorganization following ischemic challenge (Arboleda-Velasquez et al., 2008). More recently, two transgenic mouse lines carrying distinct CADASIL mutations show hypomorphic Notch3 activity and with age develop smooth muscle cells abnormalities similar to human CADASIL (Arboleda-Velasquez et al., 2011). Therefore, it appears that inhibiting Notch signaling early after injury can provide some beneficial effects by limiting the increased inflammatory response, provided by reperfusion (Arumugam et al., 2006). On the other hand, it might be expected that long-term blockade of Notch can worsen the scenario by preventing regeneration (Hofmann and Iruela-Arispe, 2007).

In addition, Notch activation has been shown to be essential in neural stem cell proliferation in several hypoxia-ischemia rodent models (Androutsellis-Theotokis et al., 2006; Carlen et al., 2009; Chen et al., 2008a; Oya et al., 2009; Wang et al., 2009). Canonical Notch signaling is activated through a hypoxia-dependent mechanism (Johnson, 2011; Seidel et al., 2010), as well as through overexpression of the ligand (Androutsellis-Theotokis et al., 2006; Liu et al., 2011). Neural stem cells of the SGZ and SVZ, which are quiescent under physiological conditions, have been shown to proliferate following injury (Kawai et al., 2005; Lugert et al., 2010), probably in an attempt to repair brain damage. Notch signaling, which is a known neurogenic factor (Gaiano and Fishell, 2002), has been shown to be central in this process, as demonstrated by genetic and chemical loss of function models (Kawai et al., 2005; Oya et al., 2009; Wang et al., 2009; Xin et al., 2006). Interestingly, this regenerative potential, in response to injury, is diminished with aging (Lugert et al., 2010).

Some time after stroke, attenuation of Notch signaling appears to be required for integration of newly born neurons in the hippocampal network (Oya et al., 2009). On the other hand, a recent report has shown that 1 week after kainate injury, Notch-dependent stem cell proliferation is short-lived and cell fate commitment, mainly of astroglial type, occurs (Sibbe et al., 2012). This discrepancy might be explained by distinct microenvironmental reactions in hypoxia-ischemia and ischemia where Notch-DSL interactions with either Jagged1 or Deltalike1 lead to neurogenic (Nyfeler et al., 2005) or gliogenic commitment (Grandbarbe et al., 2003), respectively. Application of exogenous Jagged1 might promote the neurogenic potential in the sclerotic scar and provide a beneficial influence in terms of regeneration and neuronal replenishment.

Interestingly, it has recently been proposed that canonical Notch signaling is induced by isofluorane preconditioning and can mediate neuroprotective functions following focal ischemia (Yang et al., 2012). It has been proposed that preconditioning, using sub-lethal insults, can activate signaling cascades such as NF- $\mathrm{\kappa B}$ and HIF that have neuroprotective functions (Gidday, 2006). It is possible that Notch activation, through a yet unknown mechanism, takes part in these pro-survival processes. Interestingly, a recently identified neuroprotective gene, Botch (Dai et al., 2010), can regulate Notch expression (Chi et al., 2012). Similar dual functions have also been described for another pathway: PIK3/AKT (Brown, 2007; Sawe et al., 
2008), which has been intimately connected to Notch in the survival/death choice in cancer (Calzavara et al., 2008; Chan et al., 2007; Gutierrez and Look, 2007; Palomero et al., 2007).

On the whole, it appears that several Notch-dependent processes are triggered by cerebral hypoxia-ischemia. Understanding the molecular dynamics of this signaling cascade will help devise more effective therapeutic approaches that influence this pathway and can limit brain damage and favor regeneration.

\section{Conclusions}

In this review, we have focused on the role of Notch signaling in the mature brain. We have attempted to give an overview collecting significant findings from past and present investigations. It emerges that Notch is critical for physiological brain functions from neurogenesis to memory processing. In addition, aberrant activation following brain injury appears to contribute on one side to neuronal demise, triggering apoptotic processes and increasing inflammatory responses, and on the other side to regeneration. The molecular mechanisms beyond such diverse functions are currently a subject of intense study and we expect it to increase in the future. For the yet unsolved mechanisms, we have looked at other biological models such as development and cancer, where Notch has been extensively studied. In this way, we have tried to fill the current biological gap in order to find possible explanations for Notch function in the mature brain. We have also reported brain diseases, such as $\mathrm{AD}$ and stroke, where Notch signaling alterations are reported. We have also mentioned some of the challenges in drug development that target $\gamma$-secretase dysfunctions due to off-target effects on the Notch pathway. We believe that this cascade, at the pace of other highly conserved pathways, plays a crucial role in brain physiology and pathology. We expect that in the next decade, several breakthrough discoveries will be made, connecting the dots in the brain "signalome". These works will help the development of new therapeutic strategies for the prevention and treatment of brain disease in which Notch is directly implicated.

\section{Acknowledgments}

We would like to thank Nicholas Gaiano, Cedric Wesley, Shuxi Liu and Robert Kretz for their helpful contribution to this manuscript. This research is supported entirely by the Swiss National Foundation, Synapsis Foundation and Swiss Heart Association.

\section{References}

Alagille, D., Odievre, M., Gautier, M., Dommergues, J.P., 1975. Hepatic ductular hypoplasia associated with characteristic facies, vertebral malformations, retarded physical, mental, and sexual development, and cardiac murmur. Journal of Pediatrics 86, 63-71.

Alberi, L., Chi, Z., Kadam, S.D., Mulholland, J.D., Dawson, V.L., Gaiano, N., Comi, A.M., 2010. Neonatal stroke in mice causes long-term changes in neuronal Notch-2 expression that may contribute to prolonged injury. Stroke 41, S64-S71.

Alberi, L., Liu, S., Wang, Y., Badie, R., Smith-Hicks, C., Wu, J., Pierfelice, T.J., Abazyan, B., Mattson, M.P., Kuhl, D., Pletnikov, M., Worley, P.F., Gaiano, N., 2011. Activityinduced Notch signaling in neurons requires Arc/Arg3.1 and is essential for synaptic plasticity in hippocampal networks. Neuron 69, 437-444.

Andersen, P., Uosaki, H., Shenje, L.T., Kwon, C., 2012. Non-canonical Notch signaling: emerging role and mechanism. Trends in Cell Biology 22, 257-265.

Androutsellis-Theotokis, A., Leker, R.R., Soldner, F., Hoeppner, D.J., Ravin, R., Poser, S.W., Rueger, M.A., Bae, S.K., Kittappa, R., McKay, R.D., 2006. Notch signalling regulates stem cell numbers in vitro and in vivo. Nature 442, 823-826.

Ann, E.J., Kim, H.Y., Seo, M.S., Mo, J.S., Kim, M.Y., Yoon, J.H., Park, H.S., 2012. Wnt5a controls Notch1 signaling through CaMKII mediated degradation of the SMRT corepressor protein. Journal of Biological Chemistry.

Arboleda-Velasquez, J.F., Manent, J., Lee, J.H., Tikka, S., Ospina, C., Vanderburg, C.R., Frosch, M.P., Rodriguez-Falcon, M., Villen, J., Gygi, S., Lopera, F., Kalimo, H., Moskowitz, M.A., Ayata, C., Louvi, A., Artavanis-Tsakonas, S., 2011. Hypomorphic Notch 3 alleles link Notch signaling to ischemic cerebral small-vessel disease.
Proceedings of the National Academy of Sciences of the United States of America 108, E128-E135.

Arboleda-Velasquez, J.F., Zhou, Z., Shin, H.K., Louvi, A., Kim, H.H., Savitz, S.I., Liao, J.K., Salomone, S., Ayata, C., Moskowitz, M.A., Artavanis-Tsakonas, S., 2008. Linking Notch signaling to ischemic stroke. Proceedings of the National Academy of Sciences of the United States of America 105, 4856-4861.

Artavanis-Tsakonas, S., Rand, M.D., Lake, R.J., 1999. Notch signaling: cell fate control and signal integration in development. Science 284, 770-776.

Arumugam, T.V., Chan, S.L., Jo, D.G., Yilmaz, G., Tang, S.C., Cheng, A., Gleichmann, M., Okun, E., Dixit, V.D., Chigurupati, S., Mughal, M.R., Ouyang, X., Miele, L., Magnus, T., Poosala, S., Granger, D.N., Mattson, M.P., 2006. Gamma secretasemediated Notch signaling worsens brain damage and functional outcome in ischemic stroke. Nature Medicine 12, 621-623.

Arumugam, T.V., Cheng, Y.L., Choi, Y., Choi, Y.H., Yang, S., Yun, Y.K., Park, J.S., Yang, D.K., Thundyil, J., Gelderblom, M., Karamyan, V.T., Tang, S.C., Chan, S.L., Magnus, T., Sobey, C.G., Jo, D.G., 2011. Evidence that gamma-secretase-mediated Notch signaling induces neuronal cell death via the nuclear factor-kappaB-Bcl2 -interacting mediator of cell death pathway in ischemic stroke. Molecular Pharmacology 80, 23-31.

Ataman, B., Ashley, J., Gorczyca, M. Ramachandran, P. Fouquet W. Sigrist, S.J., Budnik, V., 2008. Rapid activity-dependent modifications in synaptic structure and function require bidirectional Wnt signaling. Neuron 57, 705-718.

Basak, O., Giachino, C., Fiorini, E., Macdonald, H.R., Taylor, V., 2012. Neurogenic subventricular zone stem/progenitor cells are Notch1-dependent in their active but not quiescent state. Journal of Neuroscience 32,5654-5666.

Basak, O., Taylor, V., 2007. Identification of self-replicating multipotent progenitors in the embryonic nervous system by high Notch activity and Hes5 expression. European Journal of Neuroscience 25, 1006-1022.

Bash, J., Zong, W.X., Banga, S., Rivera, A., Ballard, D.W., Ron, Y., Gelinas, C., 1999. Rel/NF-kappaB can trigger the Notch signaling pathway by inducing the expression of Jagged1, a ligand for Notch receptors. EMBO Journal 18, 2803-2811.

Becam, I., Fiuza, U.M., Arias, A.M., Milan, M., 2010. A role of receptor Notch in ligand cis-inhibition in Drosophila. Current Biology 20, 554-560.

Beffert, U., Weeber, E.J., Durudas, A., Qiu, S., Masiulis, I., Sweatt, J.D., Li, W.P., Adelmann, G., Frotscher, M., Hammer, R.E., Herz, J., 2005. Modulation of synaptic plasticity and memory by Reelin involves differential splicing of the lipoprotein receptor Apoer2. Neuron 47, 567-579.

Bekinschtein, P., Katche, C., Slipczuk, L.N., Igaz, L.M., Cammarota, M., Izquierdo, I., Medina, J.H., 2007. mTOR signaling in the hippocampus is necessary for memory formation. Neurobiology of Learning and Memory 87, 303-307.

Ben Abdallah, N.M., Slomianka, L., Vyssotski, A.L., Lipp, H.P., 2010. Early age-related changes in adult hippocampal neurogenesis in C 57 mice. Neurobiology of Aging $31,151-161$

Berezovska, O., McLean, P., Knowles, R., Frosh, M., Lu, F.M., Lux, S.E., Hyman, B.T., 1999. Notch1 inhibits neurite outgrowth in postmitotic primary neurons. Neuroscience $93,433-439$.

Berezovska, O., Xia, M.Q., Hyman, B.T., 1998. Notch is expressed in adult brain, is coexpressed with presenilin-1, and is altered in Alzheimer disease. Journal of Neuropathology and Experimental Neurology 57, 738-745.

Bergami, M., Berninger, B., Canossa, M., 2009. Conditional deletion of TrkB alters adult hippocampal neurogenesis and anxiety-related behavior. Communicative and Integrative Biology 2,14-16.

Bonini, S.A., Ferrari-Toninelli, G., Uberti, D., Montinaro, M., Buizza, L., Lanni, C., Grilli, M., Memo, M., 2011. Nuclear factor kappaB-dependent neurite remodeling is mediated by Notch pathway. Journal of Neuroscience 31, 11697-11705.

Breunig, J.J., Silbereis, J., Vaccarino, F.M., Sestan, N., Rakic, P., 2007. Notch regulates cell fate and dendrite morphology of newborn neurons in the postnatal dentate gyrus. Proceedings of the National Academy of Sciences of the United States of America 104, 20558-20563.

Brown, I.R., 2007. Heat shock proteins and protection of the nervous system. Annals of the New York Academy of Sciences 1113, 147-158.

Brown, J., Cooper-Kuhn, C.M., Kempermann, G., Van Praag, H., Winkler, J., Gage, F.H., Kuhn, H.G., 2003. Enriched environment and physical activity stimulate hippocampal but not olfactory bulb neurogenesis. European Journal of Neuroscience 17, 2042-2046.

Bruel-Jungerman, E., Veyrac, A., Dufour, F., Horwood, J., Laroche, S., Davis, S., 2009. Inhibition of PI3K-Akt signaling blocks exercise-mediated enhancement of adult neurogenesis and synaptic plasticity in the dentate gyrus. PLoS ONE 4, e7901.

Calzavara, E., Chiaramonte, R., Cesana, D., Basile, A., Sherbet, G.V., Comi, P., 2008. Reciprocal regulation of Notch and PI3 K/Akt signalling in T-ALL cells in vitro. Journal of Cellular Biochemistry 103, 1405-1412.

Carlen, M., Meletis, K., Goritz, C., Darsalia, V., Evergren, E., Tanigaki, K., Amendola, M., Barnabe-Heider, F., Yeung, M.S., Naldini, L., Honjo, T., Kokaia, Z., Shupliakov, O., Cassidy, R.M., Lindvall, O., Frisen, J., 2009. Forebrain ependymal cells are Notch-dependent and generate neuroblasts and astrocytes after stroke. Nature Neuroscience 12, 259-267.

Chan, S.M., Weng, A.P., Tibshirani, R., Aster, J.C., Utz, P.J., 2007. Notch signals positively regulate activity of the mTOR pathway in T-cell acute lymphoblastic leukemia. Blood 110, 278-286.

Chao, M.Y., Larkins-Ford, J., Tucey, T.M., Hart, A.C., 2005. lin-12 Notch functions in the adult nervous system of C. elegans. BMC Neuroscience 6, 45

Chavez, J.C., LaManna, J.C., 2002. Activation of hypoxia-inducible factor-1 in the rat cerebral cortex after transient global ischemia: potential role of insulin-like growth factor-1. Journal of Neuroscience 22, 8922-8931.

Chavez-Gutierrez, L., Bammens, L., Benilova, I., Vandersteen, A., Benurwar, M., Borgers, M., Lismont, S., Zhou, L., Van Cleynenbreugel, S., Esselmann, H., Wiltfang, J., 
Serneels, L., Karran, E., Gijsen, H., Schymkowitz, J., Rousseau, F., Broersen, K., De Strooper, B. 2012. The mechanism of gamma-Secretase dysfunction in familial Alzheimer disease. EMBO Journal.

Chen, J., Zacharek, A., Li, A., Cui, X., Roberts, C., Lu, M., Chopp, M., 2008a. Atorvastatin promotes presenilin-1 expression and Notch 1 activity and increases neural progenitor cell proliferation after stroke. Stroke 39, 220-226.

Chen, Q., Nakajima, A., Choi, S.H., Xiong, X., Sisodia, S.S., Tang, Y.P., 2008b. Adult neurogenesis is functionally associated with AD-like neurodegeneration. Neurobiology of Disease 29, 316-326.

Cheng, P., Zlobin, A., Volgina, V., Gottipati, S., Osborne, B., Simel, E.J., Miele, L., Gabrilovich, D.I., 2001. Notch-1 regulates NF-kappaB activity in hemopoietic progenitor cells. Journal of Immunology 167, 4458-4467.

Chevallier, N.L., Soriano, S., Kang, D.E., Masliah, E., Hu, G., Koo, E.H., 2005. Perturbed neurogenesis in the adult hippocampus associated with presenilin-1 A246E mutation. American Journal of Pathology 167, 151-159.

Chi, Z., Zhang, J., Tokunaga, A., Harraz, M.M., Byrne, S.T., Dolinko, A., Xu, J., Blackshaw, S., Gaiano, N., Dawson, T.M., Dawson, V.L., 2012. Botch promotes neurogenesis by antagonizing Notch. Developmental Cell 22, 707-720.

Childress, J.L., Acar, M., Tao, C., Halder, G., 2006. Lethal giant discs, a novel C2domain protein, restricts notch activation during endocytosis. Current Biology $16,2228-2233$.

Cisse, M., Duplan, E., Guillot-Sestier, M.V., Rumigny, J., Bauer, C., Pages, G., Orzechowski, H.D., Slack, B.E., Checler, F., Vincent, B., 2011. The extracellular regulated kinase-1 (ERK1) controls regulated alpha-secretase-mediated processing, promoter transactivation, and mRNA levels of the cellular prion protein. Journal of Biological Chemistry 286, 29192-29206.

Conboy, L., Seymour, C.M., Monopoli, M.P., O‘Sullivan, N.C., Murphy, K.J., Regan, C.M., 2007. Notch signalling becomes transiently attenuated during long-term memory consolidation in adult Wistar rats. Neurobiology of Learning and Memory $88,342-351$

Costa, R.M., Honjo, T., Silva, A.J., 2003. Learning and memory deficits in Notch mutant mice. Current Biology 13, 1348-1354.

Crowner, D., Le Gall, M., Gates, M.A., Giniger, E., 2003. Notch steers Drosophila ISNb motor axons by regulating the Abl signaling pathway. Current Biology 13, 967-972.

D‘Souza, B., Miyamoto, A., Weinmaster, G., 2008. The many facets of Notch ligands. Oncogene 27, 5148-5167.

Dahlhaus, M., Hermans, J.M., Van Woerden, L.H., Saiepour, M.H., Nakazawa, K., Mansvelder, H.D., Heimel, J.A., Levelt, C.N., 2008. Notch1 signaling in pyramidal neurons regulates synaptic connectivity and experience-dependent modifications of acuity in the visual cortex. Journal of Neuroscience 28, 10794-10802.

Dai, C., Liang, D., Li, H., Sasaki, M., Dawson, T.M., Dawson, V.L., 2010. Functional identification of neuroprotective molecules. PLoS ONE 5, e15008.

Dang, L, Fan, X., Chaudhry, A., Wang, M. Gaiano, N., Eberhart, C.G., 2006. Notch3 signaling initiates choroid plexus tumor formation. Oncogene 25, 487-491.

de Bivort, B.L., Guo, H.F., Zhong, Y., 2009. Notch Signaling Is Required for Activity-Dependent Synaptic Plasticity at the Drosophila Neuromuscular Junction. Journal of Neurogenetics, 1-10.

de Celis, J.F., Bray, S., 1997. Feed-back mechanisms affecting Notch activation at the dorsoventral boundary in the Drosophila wing. Development 124, 3241-3251.

de la Pompa, J.L., Wakeham, A., Correia, K.M., Samper, E., Brown, S., Aguilera, R.J., Nakano, T., Honjo, T., Mak, T.W., Rossant, J., Conlon, R.A., 1997. Conservation of the Notch signalling pathway in mammalian neurogenesis. Development 124 , 1139-1148.

del Alamo, D., Schweisguth, F., 2009. Notch signalling: receptor cis-inhibition to achieve directionality. Current Biology 19, R683-R684.

Del Monte, G., Grego-Bessa, J., Gonzalez-Rajal, A., Bolos, V., De La Pompa, J.L., 2007. Monitoring Notch1 activity in development: evidence for a feedback regulatory loop. Developmental Dynamics 236, 2594-2614.

Dichgans, M., 2007. Genetics of ischaemic stroke. The Lancet Neurology 6, 149-161.

Ehm, O., Goritz, C., Covic, M., Schaffner, I., Schwarz, T.J., Karaca, E., Kempkes, B., Kremmer, E., Pfrieger, F.W., Espinosa, L., Bigas, A., Giachino, C., Taylor, V., Frisen, J., Lie, D.C., 2010. RBPJkappa-dependent signaling is essential for long-term maintenance of neural stem cells in the adult hippocampus. Journal of Neuroscience 30, 13794-13807.

Eiraku, M., Hirata, Y., Takeshima, H., Hirano, T., Kengaku, M., 2002. Delta/notchlike epidermal growth factor (EGF)-related receptor, a novel EGF-like repeatcontaining protein targeted to dendrites of developing and adult central nervous system neurons. Journal of Biological Chemistry 277, 25400-25407.

Espinosa, L., Santos, S., Ingles-Esteve, J., Munoz-Canoves, P., Bigas, A., 2002. p65-NFkappaB synergizes with Notch to activate transcription by triggering cytoplasmic translocation of the nuclear receptor corepressor N-CoR. Journal of Cell Science 115, 1295-1303.

Fassa, A., Mehta, P., Efthimiopoulos, S., 2005. Notch 1 interacts with the amyloid precursor protein in a Numb-independent manner. Journal of Neuroscience Research 82, 214-224.

Faure, A., Verret, L., Bozon, B., El Tannir El Tayara, N., Ly, M., Kober, F., Dhenain, M., Rampon, C., Delatour, B., 2011. Impaired neurogenesis, neuronal loss, and brain functional deficits in the APPxPS1-Ki mouse model of Alzheimer's disease. Neurobiology of Aging 32, 407-418.

Ferrari Toninelli, G., Bernardi, C., Quarto, M., Lozza, G., Memo, M., Grilli, M., 2003. Long-lasting induction of Notch2 in the hippocampus of kainate-treated adult mice. Neuroreport 14, 917-921.

Ferron, S.R., Marques-Torrejon, M.A., Mira, H., Flores, I., Taylor, K., Blasco, M.A., Farinas, I., 2009. Telomere shortening in neural stem cells disrupts neuronal differentiation and neuritogenesis. Journal of Neuroscience 29, 14394-14407.
Fischer, D.F., van Dijk, R., Sluijs, J.A., Nair, S.M., Racchi, M., Levelt, C.N., van Leeuwen, F.W., Hol, E.M., 2005. Activation of the Notch pathway in Down syndrome: cross-talk of Notch and APP. FASEB Journal 19, 1451-1458.

Fortini, M.E., Artavanis-Tsakonas, S., 1994. The suppressor of hairless protein participates in notch receptor signaling. Cell 79, 273-282.

Franklin, J.L., Berechid, B.E., Cutting, F.B., Presente, A., Chambers, C.B., Foltz, D.R., Ferreira, A., Nye, J.S., 1999. Autonomous and non-autonomous regulation of mammalian neurite development by Notch1 and Delta1. Current Biology 9, $1448-1457$.

Fre, S., Hannezo, E., Sale, S., Huyghe, M., Lafkas, D., Kissel, H., Louvi, A., Greve, J., Louvard, D. Artavanis-Tsakonas, S, 2011. Notch lineages and activity in intestinal stem cells determined by a new set of knock-in mice. PLoS ONE 6, e25785.

Fryer, C.J., White, J.B., Jones, K.A., 2004. Mastermind recruits CycC:CDK8 to phosphorylate the Notch ICD and coordinate activation with turnover. Molecular Cell $16,509-520$.

Gaiano, N., Fishell, G., 2002. The role of notch in promoting glial and neural stem cell fates. Annual Review of Neuroscience 25, 471-490.

Garaschuk, O., Linn, J., Eilers, J., Konnerth, A., 2000. Large-scale oscillatory calcium waves in the immature cortex. Nature Neuroscience 3, 452-459.

Gazave, E. Lapebie, P., Richards, G.S., Brunet, F., Ereskovsky, A.V., Degnan, B.M. Borchiellini, C., Vervoort, M., Renard, E., 2009. Origin and evolution of the Notch signalling pathway: an overview from eukaryotic genomes. BMC Evolutionary Biology $9,249$.

Ge, C., Stanley, P., 2008. The O-fucose glycan in the ligand-binding domain of Notch1 regulates embryogenesis and T cell development. Proceedings of the National Academy of Sciences of the United States of America 105, 1539-1544.

Ge, X., Hannan, F., Xie, Z., Feng, C., Tully, T., Zhou, H., Zhong, Y., 2004. Notch signaling in Drosophila long-term memory formation. Proceedings of the National Academy of Sciences of the United States of America 101, 10172-10176.

Gidday, J.M., 2006. Cerebral preconditioning and ischaemic tolerance. Nature Reviews Neuroscience 7, 437-448.

Giniger, E., 1998. A role for Abl in Notch signaling. Neuron 20, 667-681.

Glittenberg, M., Pitsouli, C., Garvey, C., Delidakis, C., Bray, S., 2006. Role of conserved intracellular motifs in Serrate signalling, cis-inhibition and endocytosis. EMBO Journal 25, 4697-4706.

Grandbarbe, L., Bouissac, J., Rand, M., Hrabe de Angelis, M., Artavanis-Tsakonas, S., Mohier, E., 2003. Delta-Notch signaling controls the generation of neurons/glia from neural stem cells in a stepwise process. Development 130 , 1391-1402.

Gustafsson, M.V., Zheng, X., Pereira, T., Gradin, K., Jin, S., Lundkvist, J., Ruas, J.L., Poellinger, L., Lendahl, U., Bondesson, M., 2005. Hypoxia requires notch signaling to maintain the undifferentiated cell state. Developmental Cell 9, 617-628.

Gutierrez, A., Look, A.T., 2007. NOTCH and PI3K-AKT pathways intertwined. Cancer Cell 12, 411-413.

Hanz, S., Perlson, E., Willis, D., Zheng, J.Q., Massarwa, R., Huerta, J.J., Koltzenburg, M., Kohler, M., van-Minnen, J., Twiss, J.L., Fainzilber, M., 2003. Axoplasmic importins enable retrograde injury signaling in lesioned nerve. Neuron 40, 1095-1104.

Hashimoto-Torii, K., Torii, M., Sarkisian, M.R., Bartley, C.M., Shen, J., Radtke, F., Gridley, T., Sestan, N., Rakic, P., 2008. Interaction between Reelin and Notch signaling regulates neuronal migration in the cerebral cortex. Neuron 60, 273-284.

Herz, J., Chen, Y., 2006. Reelin, lipoprotein receptors and synaptic plasticity. Nature Reviews Neuroscience 7, 850-859.

Hicks, C., Ladi, E., Lindsell, C., Hsieh, J.J., Hayward, S.D., Collazo, A., Weinmaster, G., 2002. A secreted Delta1-Fc fusion protein functions both as an activator and inhibitor of Notch1 signaling. Journal of Neuroscience Research 68, 655-667.

Hoeck, J.D., Jandke, A., Blake, S.M., Nye, E., Spencer-Dene, B., Brandner, S., Behrens, A., 2010. Fbw7 controls neural stem cell differentiation and progenitor apoptosis via Notch and c-Jun. Nature Neuroscience 13, 1365-1372.

Hoeffer, C.A., Tang, W., Wong, H., Santillan, A., Patterson, R.J., Martinez, L.A., TejadaSimon, M.V., Paylor, R., Hamilton, S.L., Klann, E., 2008. Removal of FKBP12 enhances mTOR-Raptor interactions, LTP, memory, and perseverative/repetitive behavior. Neuron 60, 832-845.

Hoey, S.E., Williams, R.J., Perkinton, M.S., 2009. Synaptic NMDA receptor activation stimulates alpha-secretase amyloid precursor protein processing and inhibits amyloid-beta production. Journal of Neuroscience 29, 4442-4460.

Hofmann, J.J., Iruela-Arispe, M.L., 2007. Notch signaling in blood vessels: who is talking to whom about what? Circulation Research 100, 1556-1568.

Hori, K., Sen, A., Kirchhausen, T., Artavanis-Tsakonas, S., 2011. Synergy between the ESCRT-III complex and Deltex defines a ligand-independent Notch signal. Journal of Cell Biology 195, 1005-1015.

Hou, L., Klann, E., 2004. Activation of the phosphoinositide 3-kinase-Aktmammalian target of rapamycin signaling pathway is required for metabotropic glutamate receptor-dependent long-term depression. Journal of Neuroscience 24, 6352-6361.

Huang, Q., Raya, A., DeJesus, P., Chao, S.H., Quon, K.C., Caldwell, J.S., Chanda, S.K., Izpisua-Belmonte, J.C., Schultz, P.G., 2004. Identification of p53 regulators by genome-wide functional analysis. Proceedings of the National Academy of Sciences of the United States of America 101, 3456-3461.

Huenniger, K., Kramer, A., Soom, M., Chang, I., Kohler, M., Depping, R., Kehlenbach, R.H., Kaether, C., 2010. Notch1 signaling is mediated by importins alpha 3, 4, and 7. Cellular and Molecular Life Sciences 67, 3187-3196.

Imayoshi, I. Kageyama, R., 2011. The role of Notch signaling in adult neurogenesis. Molecular Neurobiology 44, 7-12.

Imayoshi, I., Sakamoto, M., Yamaguchi, M., Mori, K., Kageyama, R., 2010. Essential roles of Notch signaling in maintenance of neural stem cells in developing and adult brains. Journal of Neuroscience 30, 3489-3498. 
Ishikawa, Y., Onoyama, I., Nakayama, K.I., Nakayama, K., 2008. Notch-dependent cell cycle arrest and apoptosis in mouse embryonic fibroblasts lacking Fbxw7. Oncogene 27, 6164-6174

Ishikura, N., Clever, J.L., Bouzamondo-Bernstein, E., Samayoa, E., Prusiner, S.B., Huang, E.J., DeArmond, S.J., 2005. Notch-1 activation and dendritic atrophy in prion disease. Proceedings of the National Academy of Sciences of the United States of America 102, 886-891.

Iso, T., Kedes, L., Hamamori, Y., 2003. HES and HERP families: multiple effectors of the Notch signaling pathway. Journal of Cellular Physiology 194, 237-255.

Jafar-Nejad, H., Norga, K., Bellen, H., 2002. Numb: Adapting" notch for endocytosis. Developmental Cell 3, 155-156.

Jaskelioff, M., Muller, F.L., Paik, J.H., Thomas, E., Jiang, S., Adams, A.C., Sahin, E., Kost-Alimova, M., Protopopov, A., Cadinanos, J., Horner, J.W., Maratos-Flier, E., Depinho, R.A., 2011. Telomerase reactivation reverses tissue degeneration in aged telomerase-deficient mice. Nature 469, 102-106.

Johnson, E.A., 2011. HIF takes it up a notch. Science Signaling 4, pe33.

Joutel, A., Chabriat, H., Vahedi, K., Domenga, V., Vayssiere, C., Ruchoux, M.M., Lucas, C., Leys, D., Bousser, M.G., Tournier-Lasserve, E., 2000. Splice site mutation causing a seven amino acid Notch3 in-frame deletion in CADASIL. Neurology 54, 1874-1875.

Kameda, M., Taylor, C.J., Walker, T.L., Black, D.M., Abraham, W.C., Bartlett, P.F., 2012. Activation of latent precursors in the hippocampus is dependent on long-term potentiation. Translational Psychiatry 2, e72.

Kawai, T., Takagi, N., Nakahara, M., Takeo, S., 2005. Changes in the expression of Hes5 and Mash1 mRNA in the adult rat dentate gyrus after transient forebrain ischemia. Neuroscience Letters 380, 17-20.

Kempermann, G., Gage, F.H., 2002. Genetic determinants of adult hippocampal neurogenesis correlate with acquisition, but not probe trial performance, in the water maze task. European Journal of Neuroscience 16, 129-136.

Kim, S.Y., Kim, M.Y., Mo, J.S., Park, H.S., 2007. Notch1 intracellular domain suppresses APP intracellular domain-Tip60-Fe65 complex mediated signaling through physical interaction. Biochimica et Biophysica Acta 1773, 736-746.

Koeller, H.B., Ross, M.E., Glickstein, S.B., 2008. Cyclin D1 in excitatory neurons of the adult brain enhances kainate-induced neurotoxicity. Neurobiology of Disease $31,230-241$

Konietzko, U., Goodger, Z.V., Meyer, M., Kohli, B.M., Bosset, J., Lahiri, D.K., Nitsch, R.M., 2010. Co-localization of the amyloid precursor protein and Notch intracellular domains in nuclear transcription factories. Neurobiology of Aging 31, 58-73.

Koo, B.K., Lim, H.S., Song, R., Yoon, M.J., Yoon, K.J., Moon, J.S., Kim, Y.W., Kwon, M.C., Yoo, K.W., Kong, M.P., Lee, J., Chitnis, A.B., Kim, C.H., Kong, Y.Y., 2005. Mind bomb 1 is essential for generating functional Notch ligands to activate Notch. Development 132, 3459-3470.

Koo, B.K., Yoon, M.J. Yoon, KJ. Im, S.K., Kim, Y.Y., Kim, C.H., Suh, P.G., Jan, Y.N., Kong Y.Y., 2007. An obligatory role of mind bomb-1 in notch signaling of mammalian development. PLoS ONE 2, e1221.

Kopan, R., Ilagan, M.X., 2009. The canonical Notch signaling pathway: unfolding the activation mechanism. Cell 137, 216-233.

Kumar, J.P., Moses, K., 2001. EGF receptor and Notch signaling act upstream of Eyeless/Pax6 to control eye specification. Cell 104, 687-697.

Kurisu, J., Fukuda, T., Yokoyama, S., Hirano, T., Kengaku, M., 2010. Polarized targeting of DNER into dendritic plasma membrane in hippocampal neurons depends on endocytosis. Journal of Neurochemistry 113, 1598-1610.

Kwon, C., Cheng, P., King, I.N., Andersen, P., Shenje, L., Nigam, V., Srivastava, D., 2011. Notch post-translationally regulates beta-catenin protein in stem and progenitor cells. Nature Cell Biology 13, 1244-1251.

Kyriazis, G.A., Belal, C., Madan, M., Taylor, D.G., Wang, J., Wei, Z., Pattisapu, J.V., Chan, S.L., 2010. Stress-induced switch in Numb isoforms enhances Notch-dependent expression of subtype-specific transient receptor potential channel. Journal of Biological Chemistry 285, 6811-6825.

Le Borgne, R., Remaud, S., Hamel, S., Schweisguth, F., 2005. Two distinct E3 ubiquitin ligases have complementary functions in the regulation of delta and serrate signaling in Drosophila. PLoS Biology 3, e96.

Le Gall, M., De Mattei, C., Giniger, E., 2008. Molecular separation of two signaling pathways for the receptor, Notch. Developmental Biology 313, 556-567.

Leal, M.C., Surace, E.I., Holgado, M.P., Ferrari, C.C., Tarelli, R., Pitossi, F., Wisniewski, T., Castano, E.M., Morelli, L., 2012. Notch signaling proteins HES-1 and Hey-1 bind to insulin degrading enzyme (IDE) proximal promoter and repress its transcription and activity: implications for cellular Abeta metabolism. Biochimica et Biophysica Acta 1823, 227-235

Lefort, K., Mandinova, A., Ostano, P., Kolev, V., Calpini, V., Kolfschoten, I., Devgan, V., Lieb, J., Raffoul, W., Hohl, D., Neel, V., Garlick, J., Chiorino, G., Dotto, G.P., 2007. Notch1 is a p53 target gene involved in human keratinocyte tumor suppression through negative regulation of ROCK1/2 and MRCKalpha kinases. Genes and Development 21, 562-577.

Li, Y., Hibbs, M.A., Gard, A.L., Shylo, N.A., Yun, K., 2012. Genome-wide analysis of N1ICD/RBPJ targets in vivo reveals direct transcriptional regulation of Wnt, $\mathrm{SHH}$ and hippo pathway effectors by Notch1. Stem Cells 30, 741-752.

Lie, D.C., Colamarino, S.A., Song, H.J., Desire, L., Mira, H., Consiglio, A., Lein, E.S., Jessberger, S., Lansford, H., Dearie, A.R., Gage, F.H., 2005. Wnt signalling regulates adult hippocampal neurogenesis. Nature 437, 1370-1375.

Lieber, T., Kidd, S., Struhl, G., 2011. DSL-Notch signaling in the Drosophila brain in response to olfactory stimulation. Neuron $69,468-481$.

Limbourg, F.P., Takeshita, K., Radtke, F., Bronson, R.T., Chin, M.T., Liao, J.K., 2005. Essential role of endothelial Notch1 in angiogenesis. Circulation 111, 1826-1832.
Lindsell, C.E., Boulter, J., diSibio, G., Gossler, A., Weinmaster, G., 1996. Expression patterns of Jagged, Delta1, Notch1. Notch2, and Notch3 genes identify ligandreceptor pairs that may function in neural development. Molecular and Cellular Neurosciences 8, 14-27.

Lindsell, C.E., Shawber, C.J., Boulter, J., Weinmaster, G., 1995. Jagged: a mammalian ligand that activates Notch1. Cell 80, 909-917.

Liu, X.S., Chopp, M., Zhang, R.L., Tao, T., Wang, X.L., Kassis, H., Hozeska-Solgot, A., Zhang, L., Chen, C., Zhang, Z.G., 2011. MicroRNA profiling in subventricular zone after stroke: MiR-124a regulates proliferation of neural progenitor cells through Notch signaling pathway. PLoS ONE 6, e23461.

Lou, Y.L., Guo, F., Liu, F., Gao, F.L., Zhang, P.Q., Niu, X., Guo, S.C., Yin, J.H., Wang, Y., Deng, Z.F., 2012. miR-210 activates notch signaling pathway in angiogenesis induced by cerebral ischemia. Molecular and Cellular Biochemistry 370, 45-51.

Lugert, S., Basak, O., Knuckles, P., Haussler, U., Fabel, K., Gotz, M., Haas, C.A., Kempermann, G., Taylor, V., Giachino, C., 2010. Quiescent and active hippocampal neural stem cells with distinct morphologies respond selectively to physiological and pathological stimuli and aging. Cell Stem Cell 6, 445-456.

Lugert, S., Vogt, M., Tchorz, J.S., Muller, M., Giachino, C., Taylor, V., 2012. Homeostatic neurogenesis in the adult hippocampus does not involve amplification of Ascl1(high) intermediate progenitors. Nature Communications 3, 670.

Matsumoto, A., Onoyama, I., Sunabori, T., Kageyama, R., Okano, H., Nakayama, K.I., 2011. Fbxw7-dependent degradation of Notch is required for control of stemness" and neuronal-glial differentiation in neural stem cells. Journal of Biological Chemistry 286, 13754-13764.

Matsuno, M., Horiuchi, J., Tully, T., Saitoe, M., 2009. The Drosophila cell adhesion molecule klingon is required for long-term memory formation and is regulated by Notch. Proceedings of the National Academy of Sciences of the United States of America 106, 310-315.

Meffert, M.K., Baltimore, D., 2005. Physiological functions for brain NF-kappaB. Trends in Neurosciences 28, 37-43.

Meffert, M.K., Chang, J.M., Wiltgen, B.J., Fanselow, M.S., Baltimore, D., 2003. NFkappa B functions in synaptic signaling and behavior. Nature Neuroscience 6, 1072-1078.

Miller, A.C., Lyons, E.L., Herman, T.G., 2009. cis-Inhibition of Notch by endogenous Delta biases the outcome of lateral inhibition. Current Biology 19, 1378-1383.

Mizutani, K., Yoon, K., Dang, L., Tokunaga, A., Gaiano, N., 2007. Differential Notch signalling distinguishes neural stem cells from intermediate progenitors. Nature 449, 351-355.

Moehlmann, T. Winkler, E, Xia, X, Edbauer, D., Murrell, J., Capell, A, Kaether, C. Zheng, H., Ghetti, B., Haass, C., Steiner, H., 2002. Presenilin-1 mutations of leucine 166 equally affect the generation of the Notch and APP intracellular domains independent of their effect on Abeta 42 production. Proceedings of the National Academy of Sciences of the United States of America 99, 8025-8030.

Mukherjee, T., Kim, W.S., Mandal, L., Banerjee, U., 2011. Interaction between Notch and Hif-alpha in development and survival of Drosophila blood cells. Science 332, 1210-1213.

Mumm, J.S., Schroeter, E.H., Saxena, M.T., Griesemer, A., Tian, X., Pan, D.J., Ray, W.J., Kopan, R., 2000. A ligand-induced extracellular cleavage regulates gammasecretase-like proteolytic activation of Notch1. Molecular Cell 5, 197-206.

Muskavitch, M.A., 1994. Delta-notch signaling and Drosophila cell fate choice. Developmental Biology 166, 415-430.

Nagarsheth, M.H., Viehman, A., Lippa, S.M., Lippa, C.F., 2006. Notch-1 immunoexpression is increased in Alzheimer's and Pick's disease. Journal of the Neurological Sciences 244, 111-116.

Nichols, J.T., Miyamoto, A., Olsen, S.L., D‘Souza, B., Yao, C., Weinmaster, G., 2007. DSL ligand endocytosis physically dissociates Notch1 heterodimers before activating proteolysis can occur. Journal of Cell Biology 176, 445-458.

Nishimura, T., Yamaguchi, T., Tokunaga, A , Hara, A, Hamaguchi, T. Kato, K, Iwamatsu, A., Okano, H., Kaibuchi, K., 2006. Role of numb in dendritic spine development with a Cdc42 GEF intersectin and EphB2. Molecular Biology of the Cell 17, 1273-1285

Nye, J.S., Kopan, R., 1995. Developmental signaling. Vertebrate ligands for Notch. Current Biology 5, 966-969.

Nyfeler, Y., Kirch, R.D., Mantei, N., Leone, D.P., Radtke, F., Suter, U., Taylor, V., 2005. Jagged1 signals in the postnatal subventricular zone are required for neural stem cell self-renewal. EMBO Journal 24, 3504-3515.

Ohtsuka, T., Imayoshi, I., Shimojo, H., Nishi, E., Kageyama, R., McConnell, S.K., 2006. Visualization of embryonic neural stem cells using Hes promoters in transgenic mice. Molecular and Cellular Neurosciences 31, 109-122.

Okochi, M., Steiner, H., Fukumori, A., Tanii, H., Tomita, T., Tanaka, T., Iwatsubo, T., Kudo, T., Takeda, M., Haass, C., 2002. Presenilins mediate a dual intramembranous gamma-secretase cleavage of Notch-1. EMBO Journal 21,5408-5416.

Oya, S., Yoshikawa, G., Takai, K., Tanaka, J.I., Higashiyama, S., Saito, N., Kirino, T., Kawahara, N., 2009. Attenuation of Notch signaling promotes the differentiation of neural progenitors into neurons in the hippocampal CA1 region after ischemic injury. Neuroscience 158, 683-692.

Palomero, T., Sulis, M.L., Cortina, M., Real, P.., Barnes, K., Ciofani, M., Caparros, E. Buteau, J., Brown, K., Perkins, S.L., Bhagat, G., Agarwal, A.M., Basso, G., Castillo, M., Nagase, S., Cordon-Cardo, C., Parsons, R., Zuniga-Pflucker, J.C., Dominguez, M., Ferrando, A.A., 2007. Mutational loss of PTEN induces resistance to NOTCH1 inhibition in T-cell leukemia. Nature Medicine 13, 1203-1210.

Palop, J.J., Mucke, L., 2009. Epilepsy and cognitive impairments in Alzheimer disease. Archives of Neurology 66, 435-440.

Parks, A.L., Klueg, K.M., Stout, J.R., Muskavitch, M.A., 2000. Ligand endocytosis drives receptor dissociation and activation in the Notch pathway. Development 127 , $1373-1385$ 
Parr-Sturgess, C.A., Rushton, D.J., Parkin, E.T., 2010. Ectodomain shedding of the Notch ligand Jagged1 is mediated by ADAM17, but is not a lipid-raft-associated event. Biochemical Journal 432, 283-294.

Perumalsamy, L.R., Nagala, M., Banerjee, P., Sarin, A., 2009. A hierarchical cascade activated by non-canonical Notch signaling and the mTOR-Rictor complex regulates neglect-induced death in mammalian cells. Cell Death and Differentiation $16,879-889$

Pierfelice, T.J., Schreck, K.C., Dang, L., Asnaghi, L., Gaiano, N., Eberhart, C.G., 2011. Notch3 activation promotes invasive glioma formation in a tissue site-specific manner. Cancer Research 71, 1115-1125.

Pierre, K., Dupouy, B., Allard, M., Poulain, D.A., Theodosis, D.T., 2001. Mobilization of the cell adhesion glycoprotein F3/contactin to axonal surfaces is activity dependent. European Journal of Neuroscience 14, 645-656.

Placanica, L., Zhu, L., Li, Y.M., 2009. Gender- and age-dependent gamma-secretase activity in mouse brain and its implication in sporadic Alzheimer disease. PLoS ONE 4, e5088.

Rebay, I., Fleming, R.J., Fehon, R.G., Cherbas, L., Cherbas, P., Artavanis-Tsakonas, S., 1991. Specific EGF repeats of Notch mediate interactions with Delta and Serrate: implications for Notch as a multifunctional receptor. Cell 67, 687-699.

Redmond, L., Oh, S.R., Hicks, C., Weinmaster, G., Ghosh, A., 2000. Nuclear Notch1 signaling and the regulation of dendritic development. Nature Neuroscience 3 , $30-40$.

Rochefort, C., Gheusi, G., Vincent, J.D., Lledo, P.M., 2002. Enriched odor exposure increases the number of newborn neurons in the adult olfactory bulb and improves odor memory. Journal of Neuroscience 22, 2679-2689.

Rodriguez, J.J., Jones, V.C., Tabuchi, M., Allan, S.M., Knight, E.M., LaFerla, F.M., Oddo, S., Verkhratsky, A., 2008. Impaired adult neurogenesis in the dentate gyrus of a triple transgenic mouse model of Alzheimer's disease. PLoS ONE 3, e2935.

Rodriguez, J.J., Jones, V.C., Verkhratsky, A., 2009. Impaired cell proliferation in the subventricular zone in an Alzheimer's disease model. Neuroreport 20,907-912.

Roncarati, R., Sestan, N., Scheinfeld, M.H., Berechid, B.E., Lopez, P.A., Meucci, O., McGlade, J.C., Rakic, P., D‘Adamio, L., 2002. The gamma-secretase-generated intracellular domain of beta-amyloid precursor protein binds Numb and inhibits Notch signaling. Proceedings of the National Academy of Sciences of the United States of America 99, 7102-7107.

Ronchini, C., Capobianco, A.J., 2001. Induction of cyclin D1 transcription and CDK2 activity by Notch(ic): implication for cell cycle disruption in transformation by Notch(ic). Molecular and Cellular Biology 21, 5925-5934.

Sakamoto, M., Imayoshi, I., Ohtsuka, T., Yamaguchi, M., Mori, K., Kageyama, R, 2011. Continuous neurogenesis in the adult forebrain is required for innate olfactory responses. Proceedings of the National Academy of Sciences of the United States of America 108, 8479-8484

Sanalkumar, R., Dhanesh, S.B., James, J., 2010. Non-canonical activation of Notch signaling/target genes in vertebrates. Cellular and Molecular Life Sciences 67, 2957-2968.

Sato, C., Turkoz, M., Dearborn, J.T., Wozniak, D.F., Kopan, R., Hass, M.R., 2012. Loss of RBPj in postnatal excitatory neurons does not cause neurodegeneration or memory impairments in aged mice. PLoS ONE 7, e48180.

Saura, C.A., Choi, S.Y., Beglopoulos, V., Malkani, S., Zhang, D., Shankaranarayana Rao, B.S., Chattarji, S., Kelleher, R.J.3rd, Kandel, E.R., Duff, K., Kirkwood, A., Shen, J., 2004. Loss of presenilin function causes impairments of memory and synaptic plasticity followed by age-dependent neurodegeneration. Neuron 42, 23-36.

Sawe, N., Steinberg, G., Zhao, H., 2008. Dual roles of the MAPK/ERK1/2 cell signaling pathway after stroke. Journal of Neuroscience Research 86, 1659-1669.

Schroeter, E.H., Kisslinger, J.A., Kopan, R., 1998. Notch-1 signalling requires ligandinduced proteolytic release of intracellular domain. Nature 393, 382-386.

Seidel, S., Garvalov, B.K., Wirta, V., von Stechow, L., Schanzer, A., Meletis, K., Wolter, M., Sommerlad, D., Henze, A.T., Nister, M., Reifenberger, G., Lundeberg, J., Frisen, J., Acker, T., 2010. A hypoxic niche regulates glioblastoma stem cells through hypoxia inducible factor 2 alpha. Brain 133, 983-995.

Selkoe, D.J., Wolfe, M.S., 2007. Presenilin: running with scissors in the membrane. Cell 131, 215-221.

Sestan, N., Artavanis-Tsakonas, S., Rakic, P., 1999. Contact-dependent inhibition of cortical neurite growth mediated by notch signaling. Science 286, 741-746.

Shepherd, A., Wesley, U., Wesley, C., 2010. Notch and delta mRNAs in early-stage and mid-stage drosophila embryos exhibit complementary patterns of proteinproducing potentials. Developmental Dynamics 239, 1220-1233.

Shepherd, A.K., Singh, R., Wesley, C.S., 2009. Notch mRNA expression in Drosophila embryos is negatively regulated at the level of mRNA 3' processing. PLoS ONE 4, e8063.

Shimada, I.S., Borders, A., Aronshtam, A., Spees, J.L., 2011. Proliferating reactive astrocytes are regulated by Notch-1 in the peri-infarct area after stroke. Stroke 42, 3231-3237.

Sibbe, M., Forster, E., Basak, O., Taylor, V., Frotscher, M., 2009. Reelin and Notch1 cooperate in the development of the dentate gyrus. Journal of Neuroscience 29, 8578-8585.

Sibbe, M., Haussler, U., Dieni, S., Althof, D., Haas, C.A., Frotscher, M., 2012. Experimental epilepsy affects Notch1 signalling and the stem cell pool in the dentate gyrus. European Journal of Neuroscience.

Smith, E., Claudinot, S., Lehal, R., Pellegrinet, L., Barrandon, Y., Radtke, F., 2012. Generation and characterization of a Notch1 signaling-specific reporter mouse line. Genesis 50, 700-710.

Song, Y., Willer, J.R., Scherer, P.C., Panzer, J.A., Kugath, A., Skordalakes, E., Gregg, R.G., Willer, G.B., Balice-Gordon, R.J., 2010. Neural and synaptic defects in slytherin, a zebrafish model for human congenital disorders of glycosylation. PLoS ONE 5, e13743.
Souilhol, C., Cormier, S., Monet, M., Vandormael-Pournin, S., Joutel, A., Babinet, C., Cohen-Tannoudji, M. 2006. Nas transgenic mouse line allows visualization of Notch pathway activity in vivo. Genesis 44, 277-286.

Speese, S.D., Budnik, V., 2007. Wnts: up-and-coming at the synapse. Trends in Neurosciences 30, 268-275

Stanley, P., 2007. Regulation of Notch signaling by glycosylation. Current Opinion in Structural Biology 17, 530-535.

Steiner, H., Capell, A., Leimer, U., Haass, C., 1999. Genes and mechanisms involved in beta-amyloid generation and Alzheimer's disease. European Archives of Psychiatry and Clinical Neuroscience 249, 266-270.

Steiner, H., Revesz, T., Neumann, M., Romig, H., Grim, M.G., Pesold, B., Kretzschmar, H.A., Hardy, J., Holton, J.L., Baumeister, R., Houlden, H., Haass, C., 2001. A pathogenic presenilin-1 deletion causes abberrant Abeta 42 production in the absence of congophilic amyloid plaques. Journal of Biological Chemistry 276, 7233-7239.

Stoll, G., Jander, S., Schroeter, M., 1998. Inflammation and glial responses in ischemic brain lesions. Progress in Neurobiology 56, 149-171.

Stump, G., Durrer, A., Klein, A.L., Lutolf, S., Suter, U., Taylor, V., 2002. Notch1 and its ligands Delta-like and Jagged are expressed and active in distinct cell populations in the postnatal mouse brain. Mechanisms of Development 114, 153-159.

Swiatek, P.J., Lindsell, C.E., del Amo, F.F., Weinmaster, G., Gridley, T., 1994. Notch1 is essential for postimplantation development in mice. Genes and Development 8, 707-719.

Tagami, S., Okochi, M., Yanagida, K., Ikuta, A., Fukumori, A., Matsumoto, N., IshizukaKatsura, Y., Nakayama, T., Itoh, N., Jiang, J., Nishitomi, K., Kamino, K., Morihara, T., Hashimoto, R., Tanaka, T., Kudo, T., Chiba, S., Takeda, M., 2008. Regulation of Notch signaling by dynamic changes in the precision of S3 cleavage of Notch-1. Molecular and Cellular Biology 28, 165-176.

Takeshita, K., Satoh, M., Ii, M., Silver, M., Limbourg, F.P., Mukai, Y., Rikitake, Y., Radtke, F. Gridley, T., Losordo, D.W. Liao, J.K., 2007. Critical role of endothelial Notch1 signaling in postnatal angiogenesis. Circulation Research 100, 70-78.

Tanigaki, K., Nogaki, F., Takahashi, J., Tashiro, K., Kurooka, H., Honjo, T., 2001. Notch1 and Notch3 instructively restrict bFGF-responsive multipotent neural progenitor cells to an astroglial fate. Neuron 29, 45-55.

Timsit, S., Rivera, S., Ouaghi, P., Guischard, F., Tremblay, E., Ben-Ari, Y., Khrestchatisky, M., 1999. Increased cyclin D1 in vulnerable neurons in the hippocampus after ischaemia and epilepsy: a modulator of in vivo programmed cell death? European Journal of Neuroscience 11, 263-278.

Tokunaga, A., Kohyama, J., Yoshida, T., Nakao, K., Sawamoto, K., Okano, H., 2004. Mapping spatio-temporal activation of Notch signaling during neurogenesis and gliogenesis in the developing mouse brain. Journal of Neurochemistry 90 , 142-154.

Vaccari, T., Bilder, D., 2005. The Drosophila tumor suppressor vps25 prevents nonautonomous overproliferation by regulating notch trafficking. Developmental Cell 9, 687-698.

Vaccari, T., Lu, H., Kanwar, R., Fortini, M.E., Bilder, D., 2008. Endosomal entry regulates Notch receptor activation in Drosophila melanogaster. Journal of Cell Biology 180, 755-762.

van Praag, H., Kempermann, G., Gage, F.H., 1999. Running increases cell proliferation and neurogenesis in the adult mouse dentate gyrus. Nature Neuroscience 2, $266-270$.

Varela-Nallar, L., Alfaro, I.E., Serrano, F.G., Parodi, J., Inestrosa, N.C., 2010. Winglesstype family member 5A (Wnt-5a) stimulates synaptic differentiation and function of glutamatergic synapses. Proceedings of the National Academy of Sciences of the United States of America 107, 21164-21169.

Varnum-Finney, B., Wu, L., Yu, M., Brashem-Stein, C., Staats, S., Flowers, D., Griffin, J.D., Bernstein, I.D., 2000. Immobilization of Notch ligand, Delta-1, is required for induction of notch signaling. Journal of Cell Science 113 (Pt 23), 4313-4318.

Vooijs, M., Ong, C.T., Hadland, B., Huppert, S., Liu, Z., Korving, J., van den Born, M., Stappenbeck, T., Wu, Y., Clevers, H., Kopan, R., 2007. Mapping the consequence of Notch1 proteolysis in vivo with NIP-CRE. Development 134, 535-544.

Wang, X., Mao, X., Xie, L., Greenberg, D.A., Jin, K., 2009. Involvement of Notch1 signaling in neurogenesis in the subventricular zone of normal and ischemic rat brain in vivo. Journal of Cerebral Blood Flow and Metabolism 29, 1644-1654.

Wang, Y., Chan, S.L., Miele, L., Yao, P.J., Mackes, J., Ingram, D.K., Mattson, M.P., Furukawa, K., 2004. Involvement of Notch signaling in hippocampal synaptic plasticity. Proceedings of the National Academy of Sciences of the United States of America 101, 9458-9462.

Weeber, E.J., Beffert, U., Jones, C., Christian, J.M., Forster, E., Sweatt, J.D., Herz, J., 2002. Reelin and ApoE receptors cooperate to enhance hippocampal synaptic plasticity and learning. Journal of Biological Chemistry 277, 39944-39952.

Wei, Z., Chigurupati, S., Arumugam, T.V., Jo, D.G., Li, H., Chan, S.L., 2011. Notch activation enhances the microglia-mediated inflammatory response associated with focal cerebral ischemia. Stroke 42, 2589-2594.

Wolfe, M.S., 2012. gamma-Secretase inhibitors and modulators for Alzheimer's disease. Journal of Neurochemistry 120 (Suppl. 1), 89-98.

Wong, G.T., Manfra, D., Poulet, F.M., Zhang, Q. Josien, H., Bara, T., Engstrom, L. Pinzon-Ortiz, M., Fine, J.S., Lee, H.J., Zhang, L., Higgins, G.A., Parker, E.M., 2004. Chronic treatment with the gamma-secretase inhibitor LY-411,575 inhibits beta-amyloid peptide production and alters lymphopoiesis and intestinal cell differentiation. Journal of Biological Chemistry 279, 12876-12882.

Woo, H.N., Park, J.S., Gwon, A.R., Arumugam, T.V., Jo, D.G., 2009. Alzheimer's disease and Notch signaling. Biochemical and Biophysical Research Communications 390, 1093-1097.

Wu, J., Petralia, R.S., Kurushima, H., Patel, H., Jung, M.Y., Volk, L., Chowdhury, S., Shepherd, J.D., Dehoff, M., Li, Y., Kuhl, D., Huganir, R.L., Price, D.L., Scannevin, 
R., Troncoso, J.C., Wong, P.C., Worley, P.F., 2011. Arc/Arg3.1 regulates an endosomal pathway essential for activity-dependent beta-amyloid generation. Cell $147,615-628$

Xin, H., Li, Y., Chen, X., Chopp, M., 2006. Bone marrow stromal cells induce BMP2/4 production in oxygen-glucose-deprived astrocytes, which promotes an astrocytic phenotype in adult subventricular progenitor cells. Journal of Neuroscience Research 83, 1485-1493.

Yagi, H., Saito, T., Yanagisawa, M., Yu, R.K., Kato, K., 2012. Lewis X-carrying $\mathrm{N}$-glycans regulate the proliferation of mouse embryonic neural stem cells via the Notch signaling pathway. Journal of Biological Chemistry 287 24356-24364.

Yang, Q., Yan, W., Li, X., Hou, L., Dong, H., Wang, Q., Wang, S., Zhang, X., Xiong, L., 2012. Activation of canonical notch signaling pathway is involved in the ischemic tolerance induced by sevoflurane preconditioning in mice. Anesthesiology.

Yang, X., Klein, R., Tian, X., Cheng, H.T., Kopan, R., Shen, J., 2004. Notch activation induces apoptosis in neural progenitor cells through a p53-dependent pathway. Developmental Biology 269, 81-94.
Yoon, K.J., Koo, B.K., Im, S.K., Jeong, H.W., Ghim, J., Kwon, M.C., Moon, J.S., Miyata, T., Kong, Y.Y., 2008. Mind bomb 1-expressing intermediate progenitors generate notch signaling to maintain radial glial cells. Neuron 58, 519-531.

Yoon, K.J., Lee, H.R., Jo, Y.S., An, K., Jung, S.Y., Jeong, M.W., Kwon, S.K., Kim, N.S., Jeong, H.W., Ahn, S.H., Kim, K.T., Lee, K., Kim, E., Kim, J.H., Choi, J.S., Kaang, B.K., Kong, Y.Y., 2012. Mind bomb-1 is an essential modulator of long-term memory and synaptic plasticity via the Notch signaling pathway. Molecular Brain 5, 40.

Yu, H., Saura, C.A., Choi, S.Y., Sun, L.D., Yang, X., Handler, M., Kawarabayashi, T., Younkin, L., Fedeles, B., Wilson, M.A., Younkin, S., Kandel, E.R., Kirkwood, A., Shen, J., 2001. APP processing and synaptic plasticity in presenilin-1 conditional knockout mice. Neuron 31, 713-726.

Zheng, J., Watanabe, H., Wines-Samuelson, M., Zhao, H., Gridley, T., Kopan, R., Shen, J., 2012. Conditional deletion of Notch1 and Notch2 genes in excitatory neurons of postnatal forebrain does not cause neurodegeneration or reduction of Notch mRNAs and proteins. Journal of Biological Chemistry 287, 20356-20368.

Zhou, L., Li, L.W., Yan, Q., Petryniak, B., Man, Y., Su, C., Shim, J., Chervin, S., Lowe, J.B., 2008. Notch-dependent control of myelopoiesis is regulated by fucosylation. Blood 112, 308-319. 